\title{
The impact of water management on poverty and the environment in the Upper Niger River Basin (Mali)
}

\author{
Beukering, P.J.H. van ${ }^{\mathrm{a}, \mathrm{b}}$, Kone, B. ${ }^{\mathrm{c}}$, Goosen, H. ${ }^{\mathrm{b}}$ \& Zwarts, L. ${ }^{\mathrm{d}}$ \\ a Corresponding author. Beukering@ivm.vu.nl.Institute for Environmental Studies, \\ Vrije Universiteit, Amsterdam. \\ b Institute for Environmental Studies, Vrije Universiteit, Amsterdam. \\ c Wetland International, Sevare, Mali \\ d RIZA, Lelystad, Netherlands
}

\begin{abstract}
Water shortage is a severe problem for millions of people living along the southern fringe of the Sahara desert. Consequently, communities residing in the semi-arid, western Sahel zone fully depend on rivers such as the Niger for their livelihoods. Mali is a classic case of a 'riverdependent economy' that is subject to enormous seasonal variation in rainfall and river flow. A popular solution to this climate dependency in the western Sahel zone has been the development of hydro-electric and hydro-agricultural irrigation schemes.
\end{abstract}

Although Mali's hydro-electric and hydro-agricultural potential has yet to be fully realised, it is widely questioned whether the costs and benefits of such mega-investments are properly estimated. Besides the economic feasibility (i.e. direct costs and benefits) of additional dams, it is still unclear what the indirect effects of hydro-electric and hydro-agricultural schemes are on downstream $m$ beneficiaries of rivers. These beneficiaries include fishermen, cattle breeders, shipping companies and farmers, as well as the biodiversity of the river and connected floodplains.

The main objective of this study is to determine the role of dams and irrigation schemes in the overall economy and ecology of the Inner Niger Delta and the upstream region (extending across both Mali and Guinea). An integrated assessment has been conducted to determine the direct and indirect costs and benefits of different Niger River management regimes. This involved an analysis of i) potential changes to the hydrology, ii) subsequent ecological impacts, and iii) social and economic effects. Estimating the costs and benefits associated with dams in the Niger River basin required the use of various valuation techniques, such as the production function approach and the contingent valuation method.

Overall, this study recommends improving the performance of the existing infrastructure, as well as the economic activities, in the Inner Niger Delta. Our analysis shows that this is a significantly more efficient way to increase economic growth, reduce poverty and protect the environment in the region, compared to building a new dam and hydropower plant.

PREM Working Paper: 05/08

Keywords: $\quad$ Economic valuation, poverty, river basin, wetland

Date:

6 March 2005 


\section{Table of Content}

1. Introduction 1

2. Methodology 1

2.1 Cost benefit analysis of dams $\quad 2$

$\begin{array}{ll}2.2 \text { Estimation of direct costs } & 2\end{array}$

$\begin{array}{ll}2.3 \text { Estimation of indirect costs and benefits } & 3\end{array}$

$\begin{array}{ll}3 . \text { Costs } & 7\end{array}$

3.1 Sélingué $\quad 8$

$\begin{array}{lr}3.2 \text { Office du Niger } & 8\end{array}$

$\begin{array}{lr}3.3 \text { Fomi dam } & 9\end{array}$

$\begin{array}{lr}3.4 \text { Electricity } & 9\end{array}$

4. Benefits $\quad 10$

$\begin{array}{lr}4.1 \text { Fisheries } & 10\end{array}$

$\begin{array}{ll}4.2 \text { Livestock } & 11\end{array}$

$\begin{array}{lr}4.3 \text { Agriculture } & 13\end{array}$

$\begin{array}{ll}4.4 \text { Transport } & 14\end{array}$

$\begin{array}{ll}4.5 \text { Biodiversity } & 16\end{array}$

$\begin{array}{ll}\text { 5. Cost benefit analysis } & 17\end{array}$

$\begin{array}{ll}5.1 \text { Benefits and costs over time } & 17\end{array}$

$\begin{array}{ll}5.2 \text { Net present value } & 18\end{array}$

$\begin{array}{lr}5.3 \text { Sectoral distribution } & 20\end{array}$

$\begin{array}{ll}5.4 \text { Spatial distribution } & 20\end{array}$

$\begin{array}{ll}5.5 \text { Sensitivity analysis } & 24\end{array}$

$\begin{array}{ll}6 . \text { Conclusions } & 26\end{array}$

\section{Acknowledgements}

The authors would like to acknowledge funding from the Poverty Reduction and Environmental Management Project administered by the Institute for Environmental Studies (Amsterdam), as well as the Partners for Water programme administered by Wetland International (Wageningen), RIZA (Lelystad) and Altenburg \& Wymenga (Veenwouden).

WETLANDS

INTERNATIONAL

PREM apologises for not adding the Wetland International logo to the earlier version of this working paper.

\section{Poverty Reduction and Environmental Management (PREM)}

PREM aims to deepen and broaden the exposure of economic researchers and policy advisors in developing countries to the theory and methods of natural resource management and environmental economics. It is envisaged that this will encourage effective policy change in developing countries with the joint goals of poverty reduction and sustainable environmental management.

This Working Paper Series provides information about the scientific findings of the PREM projects. All publications of the PREM programme, such as working papers, press releases and policy briefs are available on the website:

www.prem-online.org 


\section{Introduction}

Mali's Poverty Reduction Strategy Paper (PRSP) constitutes the sole framework for Mali's development policies and poverty reduction strategies (GoM, 2002). This influential document highlights the need to exploit the country's hydro-electric and hydroagricultural potential in the order of 5,000 GWh/annum and 2 million hectares, respectively. A review of the PRSP by the International Development Association (IDA) and the International Monetary Fund (IMF) confirms this, and states, "further development of Mali's untapped hydrological potential is a critical need, as it directly addresses one of Mali's core vulnerabilities, that of the temporal and spatial variability in rainfall, as well as the uncertainty of climatic conditions" (IDA \& IMF, 2003).

Although Mali's hydro-electric and hydro-agricultural potential has yet to be fully realised, it is widely questioned whether the costs and benefits of such mega-investments are properly estimated. Besides the economic feasibility (i.e. direct costs and benefits) of additional dams, it is still unclear what the indirect effects of hydro-electric and hydroagricultural schemes are on downstream beneficiaries of rivers.

The overall aim of this paper is to support decision making at a basin level with regard to the management and construction of dams and irrigation schemes in the Upper-Niger, and how this may affect food security and ecological conditions downstream (in the Inner Niger Delta). This is achieved by conducting an extended cost benefit analysis (CBA) for the main economic sectors addressed in the previous chapters.

The paper is structured as follows: The methodology underlying the cost benefit analysis of dams and irrigation schemes in the Niger River basin is explained in Section 2. The valuation of the direct costs and benefits of the Office du Niger, Sélingué and the Fomi dams is described in Section 3. The indirect costs and benefits of the four scenarios are estimated in Section 4. The sectors affected indirectly include agriculture, fisheries, livestock, transport and biodiversity. In Section 5, the extended cost benefit analysis is conducted. Conclusions are drawn in Section 6.

\section{Methodology}

This study does not take a novel approach to the estimation of the costs and benefits associated with dams in the Niger River basin. Cost-Benefit Analysis (CBA) is an indispensable economic tool in any large infrastructure project. Dams are no exception. Traditionally, a CBA was performed using a limited set of parameters. In most cases the costs were restricted to the direct capital investment, construction costs and operational costs. Likewise, only direct (measurable) benefits, such as power generation, irrigation benefits and tourism were taken into account. Nowadays, social and environmental effects are increasingly considered in the planning of dams, through the application of an extended CBA. This analysis requires economic valuation of indirect costs and benefits (Aylward et al., 2001).

Several extended CBA studies on dams have been carried out in the past. The World Commission on Dams (WCD 2001) investigated eight projects in detail. Two of these are situated in Africa: (1) the Orange River Development Project in South Africa; and (2) the Lake Kariba dam in Zambia and Zimbabwe. A third interesting study in Africa, 
which was commissioned by IUCN, looked at the effects of the Maga Dam on the WazaLogone floodplain area in Cameroon (Loth 2004).

\subsection{Cost benefit analysis of dams}

Like any other large infrastructure project, dams require substantial investments in the planning and construction phase. Investments take the form of financial capital as well as technology and human resources. In comparison with initial investment costs, operation and maintenance costs for dams are relatively low. Besides initial investments and operational costs, large dam projects often have significant impacts on society and the natural environment. These represent an additional cost of the project. The best example of social impacts caused by large dam projects is the displacement and resettlement of inhabitants of the flooded area. Whereas in the past, resettlement used to be overseen in the planning phase, at present, resettlement costs are increasingly budgeted in project planning. Environmental impacts associated with dams include reduction in wetland habitat and restricted fish migration. As with social impacts, the costs of mitigating environmental impacts are more likely to be included in project planning than in the past.

\subsection{Estimation of direct costs}

Costs of dam construction projects vary significantly as a result of site characteristics. It is therefore difficult to give a general overview of the costs. Yet, we attempt this below, using information from an extensive survey on the costs of dams internationally (conducted by the World Commission on Dams (WCD, 2001)). As indicated above, direct costs of dams can be divided into 4 main categories: (1) construction costs; (2) resettlement costs; (3) environmental mitigation costs; and (4) operation and maintenance costs.

Construction costs are the major component of total project costs in most cases.

Construction costs refer to the building of the dam itself, as well as all related elements, such as turbines, canals, irrigation schemes etc. The base cost estimates are corrected with an additional 10-15\% to cover unforeseen costs, and are subsequently corrected for inflation over the construction phases. Costs depend mainly on the physical setting of the project, and vary significantly according to local geology, making it difficult to generalise about construction costs. A study by Head (1999) gives a range of US $\$ 1,000$ to US $\$ 3,000$ per KW of generated electricity for hydropower projects, while Ljung (2000) provides a range of US\$1,500 - US\$2,250 per KW.

In the past, the displacement of people and loss of livelihood resulting from reservoir flooding was not considered in project planning. Recently, resettlement and income restoration (jointly called 'resettlement costs') have received increasing attention in project design. Direct compensation of those affected is also being included in the design. Gutman (1993) found that estimated resettlement costs typically overran by $40 \%$. Resettlement costs can amount to between zero and $25 \%$ of total project costs, depending on the local demographic situation.

Dams can have large environmental impacts. To counteract negative impacts, mitigation measures are often included in the design. Examples include fish migration systems, habitat restoration and artificial flooding of wetlands. Environmental mitigation costs are 
subdivided into study costs, capital costs, operation and maintenance costs, and reporting costs. Table 1 shows an overview of these costs for hydropower projects in the USA.

Table $1 \quad$ Subdivision of Environmental costs according to size of hydropower project.

\begin{tabular}{lrrrr}
\hline $\begin{array}{l}\text { Project size } \\
\text { (installed capacity) }\end{array}$ & Capital & Type of Cost (US\$1991) & \\
\hline$<1 \mathrm{MW}$ & $\$ 134,500$ & $\$ 21,700$ & $\$ 5,124$ & $\$ 5,900$ \\
$1-10 \mathrm{MW}$ & $\$ 233,900$ & $\$ 153,200$ & $\$ 25,420$ & $\$ 11,800$ \\
$10-50 \mathrm{MW}$ & $\$ 1,511,300$ & $\$ 452,800$ & $\$ 33,000$ & $\$ 31,200$ \\
$50-100 \mathrm{MW}$ & $\$ 1,266,200$ & $\$ 1,084,000$ & $\$ 9,600$ & $\$ 500$ \\
$>100 \mathrm{MW}$ & $\$ 50,569,000$ & $\$ 307,000$ & $\$ 1,439,400$ & $\$ 176,700$ \\
\hline
\end{tabular}

Source: WCD 2001.

One of the benefits of large dam projects is that, once the construction is completed, the operational costs are proportionally lower than those of smaller dams. On average, these costs amount to only $1-3 \%$ of the total project costs. For irrigation projects, these costs are generally higher due to high maintenance costs of the irrigation network. Often the costs are covered by charging user fees for irrigation.

A recurring issue with dam projects worldwide is the enormous cost overruns. For example, a study of 70 World Bank financed hydropower project shows that the average cost overrun is around $27 \%$. In another study on multipurpose dams, costs overrun allocated budget by an average of 39\%. A WCD study (2001) into smaller dams reports overruns of as much as $200 \%$. The majority of cost overruns are due to unpredicted geotechnical conditions. Other causes include late delivery of materials, labour unrest, legal challenges, as well as changes in dam design and natural disasters. The economic performance of a dam is also influenced by how the projected time schedule compares to the actual construction time. 'Schedule slippage' amounted to $80 \%$ in a survey by the Asian Development Bank in 1995. Cost overruns and schedule slippages have large implications for the performance of dam projects. Around 8 to $10 \%$ of scheduled dams actually become financially unviable if these unforeseen overruns and slippages are taken into account (Gutman 1993, OED 1996).

\subsection{Estimation of indirect costs and benefits}

To determine the indirect costs and benefits, a wide range of information is required. A consistent way to organise this information is according to the sequence of underlying processes. This involves looking at the cause of an impact, then taking into account the physical impacts and finally considering the social and economic effects. This so-called "impact pathway approach" is a methodology that proceeds sequentially through the pathway, linking causes to impacts, and subsequently valuing these impacts. The framework of the impact pathway is shown in Figure 1 and represents the physical and socioeconomic processes resulting from the management of dams and irrigation schemes in the Niger River. The impact pathway approach proceeds in a series of methodological steps. These include: 
1. Defining the boundaries of the study: The study aims to evaluate different water management scenarios along the Niger River, with a special emphasis on the Inner Niger Delta. These scenarios include: Scenario 0: No dam or irrigation scheme; $\underline{\text { Sce- }}$ nario 1: Sélingué dam; Scenario 2: Sélingué and Office du Niger; and Scenario 3: Séligué, Office du Niger and the Fomi dam. The temporal boundaries of the project are 2005 to 2030. This period leaves enough time for the main environmental impacts to come into effect, while it is sufficiently short to make a reliable prediction about future developments.

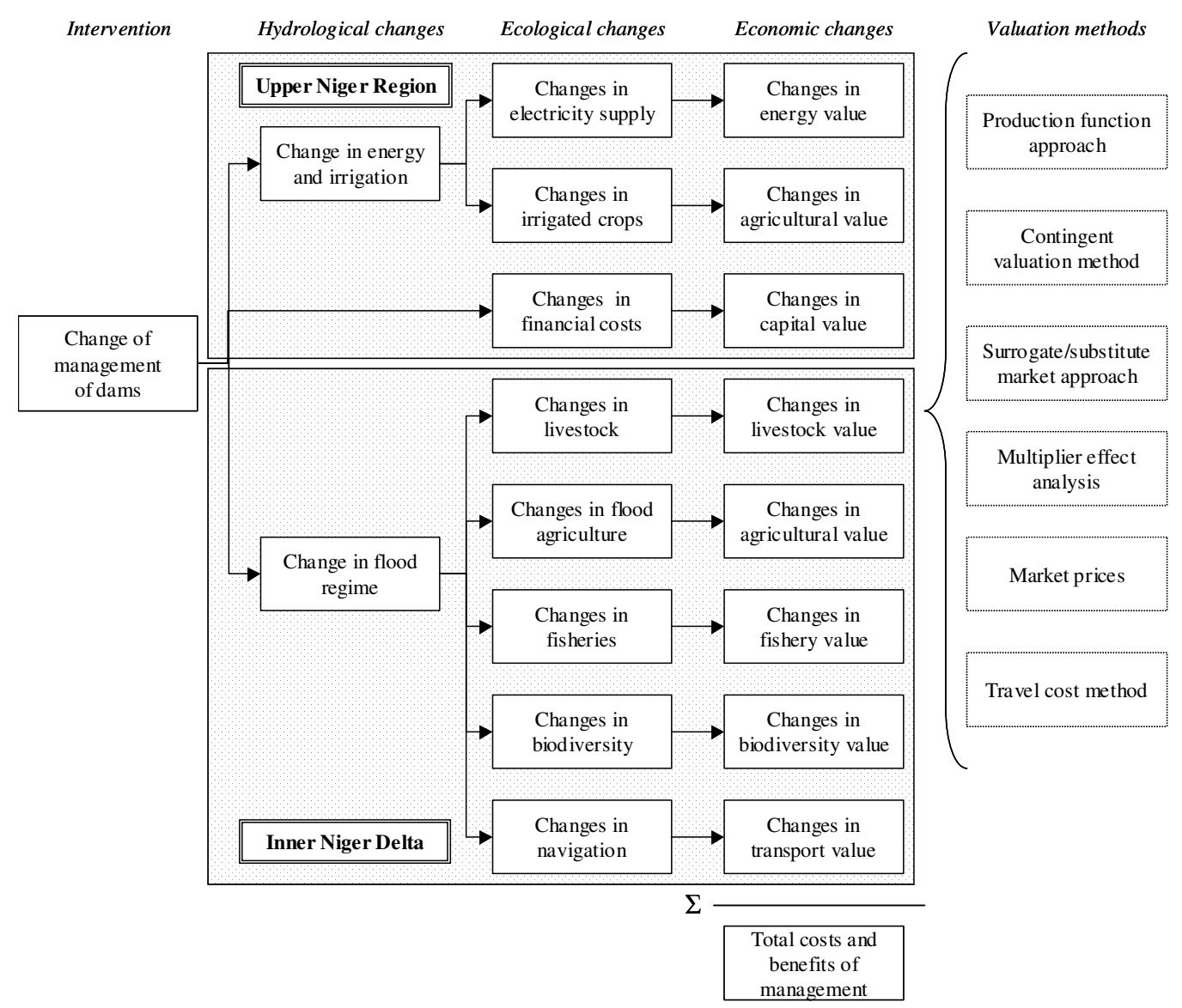

Figure 1 Impact pathway of the economic evaluation procedure of management of the Inner Niger Delta, Mali.

2. Identifying significant impacts: Due to practical limitations, the analysis includes the most significant effects only. Inevitably, judgement must be used in deciding what is and is not significant. To judge the magnitude and significance of environmental effects, a range of criteria is identified: (a) The effect on the natural and human environment depending on their relative sensitivities; (b) The location of the effect, whether within the confines of the site or beyond (local, regional, national and international scale); (c) Timing of the effect (during the construction, operational and post-operational stage); and (d) Whether the effect is reversible or irreversible. Using expert judgment for these criteria, it was decided that the impacts on fishery, agriculture, livestock, transport and biodiversity can be regarded as economic activities in the Inner Niger Delta that are significantly affected. 
Effects that are potentially significant, but on which little knowledge is available, are the health impacts of dams. On the one hand, dams and irrigation schemes improve human health because of the increased provision of food. On the other hand, they may have a negative effect on health because the expansion of stagnant water bodies boosts the occurrence of malaria and bilharzia. Due to a lack of information on health impacts, this effect has not been included in our study.

3. Physically quantifying the significant impacts: Evaluating the physical effects of the management of dams and irrigation schemes is a complex exercise. In the previous chapters, the relationship between the flooding area and the physical production levels of individual sectors has been estimated, using the production function approach. To assist in predicting the aggregated physical consequences of the various scenarios, a dynamic simulation model was developed. The model approximates the main effects of each scenario on the various benefit categories and evaluates the changes for the various districts (i.e. upstream and downstream). To calculate these impacts, simplifying assumptions were adopted, such as for climatic and hydrological conditions, and future economic activities. For example, the assumed population and population growth rates used in this study are presented in Table 2 (data from Chapter 4, Zwarts et al. 2005).

Table 2 Demographic and geographic data at the District level.

\begin{tabular}{lcc}
\hline District & Population 2004 & Growth rate (\%) \\
\hline Tombouctou & 24,858 & $0.08 \%$ \\
Gourma & 107,343 & $-1.34 \%$ \\
Goundam & 123,162 & $0.91 \%$ \\
Diré & 92,654 & $0.09 \%$ \\
Niafunké & 218,077 & $-0.34 \%$ \\
Tenenkou & 150,022 & $1.47 \%$ \\
Mopti & 335,986 & $1.54 \%$ \\
Djenne & 189,735 & $1.42 \%$ \\
Youwarou & 225,032 & $0.22 \%$ \\
Segou & 338,269 & $2.43 \%$ \\
Macina & 198,177 & $2.43 \%$ \\
Niono & 194,760 & $2.43 \%$ \\
\hline
\end{tabular}

Another crucial assumption applied in the economic analysis is one on climate. Figure 2 shows rainfall trends in the Upper Niger region and in the Inner Niger Delta for the period 1926 to 2000. Both series show a clear negative trend. In the simulation model we extrapolate the trend for the study period of 2005 to 2030. The impact of this assumption is tested through a sensitivity analysis.

Another important assumption underlying the model relates to annual climate variations. As can be observed from Figure 2, the annual rainfall in the catchment area of the Upper Niger varies between 1,100 and $1,900 \mathrm{~mm}$, with an average of 1,500 $\mathrm{mm}$. It is important to simulate these variations in the scenarios because it is generally not the average level that matters but the extremes. For example, in an extremely dry year, the impact of dams has a disproportionately large effect on the economic activities in the Inner Niger Delta. Therefore, random variations in rainfall patterns were applied in the time series of 2005 
to 2030 . The maximum variation in rainfall was set at $+/-20 \%$. The impact of both shortterm yearly variation and the long-term negative trend in climate change on the flooding area is shown in Figure 3.

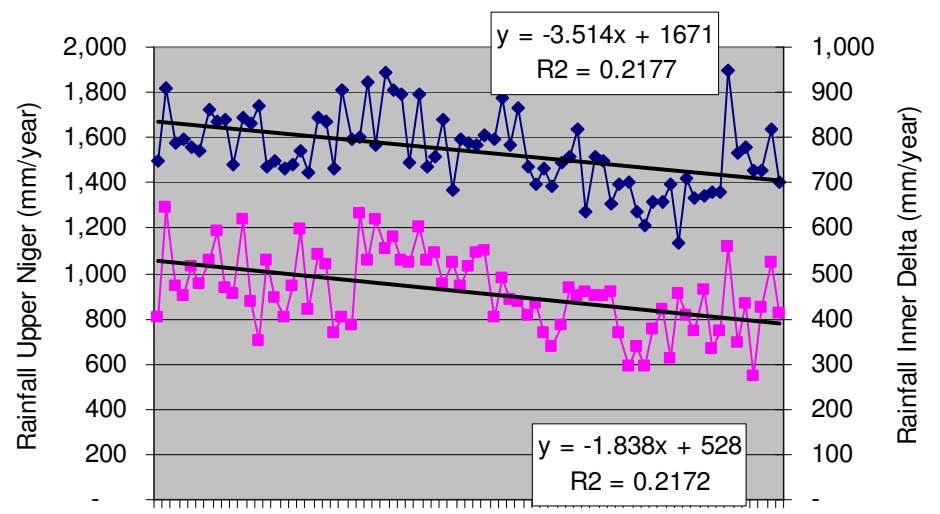

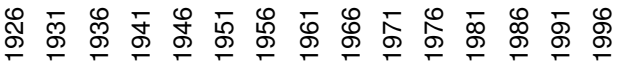

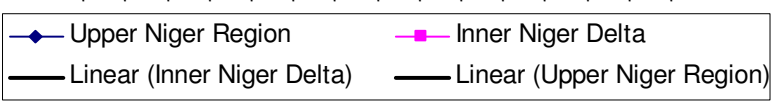

Figure 2 Rainfall trends in the Upper Niger region and the Inner Niger Delta in the period 1926 to 2002.

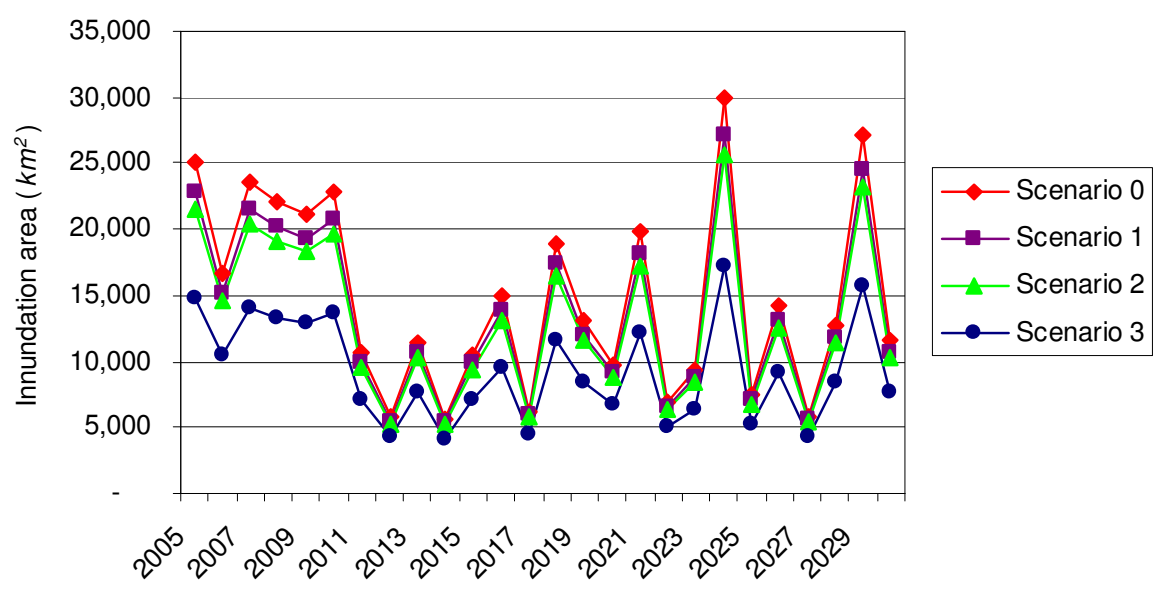

Figure 3 Simulated flooding area for the four scenarios (in $\left.\mathrm{km}^{2}\right)$.

4. Calculating monetary values and conducting a sensitivity analysis: Having established and tabulated the full range and significance of the effects, changes are valued in monetary terms. The main impact pathways covered include agriculture, fisheries, livestock, biodiversity, energy supply and transport. As shown on the righthand side of Figure 1, different valuation techniques are used for these benefits. The most commonly used valuation technique in this study is the "net factor income approach' which estimates the value of an environmental input in production by subtracting the costs of other inputs from total revenue, and ascribes the remaining surplus as the value of the environmental input. For most of the sectors considered, statistical production functions were estimated. These were incorporated in the integrated model simulating the four scenarios. The main welfare indicator of the model 
is the net-benefit of each scenario, which expresses the overall welfare level minus the financial costs of the dams and irrigation schemes. A sensitivity analysis was conducted to test the robustness of the final result, in relation to several crucial parameters such as climate change, biodiversity and the discount rate.

As shown in Figure 1, another important dimension of the impact pathway approach is the spatial allocation of welfare. Besides having an impact on the absolute level of welfare in Mali and Guinea, establishing dams in the Upper Niger region is likely to generate a transfer of economic benefits from one region to another. The model has therefore been designed at the district level, so that a distinction can be made between benefits that occur in the Inner Niger Delta (i.e. relating to livestock, agriculture, fisheries, biodiversity and transport) and those that are generated in the upstream region (i.e. electricity and irrigated crops).

\section{Box 1 Definition of costs and benefits.}

In the field of CBA, ambiguity may arise with regard to the exact definition of costs and benefits. The main basis for the demarcation of costs and benefits in this study is the stakeholders' perspectives. In this study, 'costs' only refer to direct financial effects relevant for the decision-maker who is directly responsible for the financial feasibility of the investment. These values are internal or private to the investment decision. An example cost in this study is the investment of constructing and maintaining the dams. 'Benefits' are referred to as those effects that arise external to the direct domain of the financial decision-maker. The value of benefits can be both negative (e.g. decline of fisheries in the Delta) and positive (e.g. increase of revenues from irrigation schemes).

\section{Costs}

The cost benefit analysis of the three man-made structures in the Upper Niger is somewhat unusual because it compares the Office du Niger irrigation zone and the Sélingué dam (which were established a long time ago) with the Fomi dam (which is yet to be built). To make a fair comparison, we consider a future time period of 2005 to 2030, in which we assume all dams are active and subsequently generate benefits. However, the cost side of the analysis is more complicated because, as opposed to the investments in the Fomi dam, the initial investments in Office du Niger and the Sélingué dam have already been made. These 'sunk costs' can therefore not be avoided by future decisions.

The presence of sunk costs does not imply that Office du Niger and the Sélingué dam are free of costs. Despite the fact that the initial investments were sometimes made decades ago, the dams still require maintenance and operational expenditures. In addition, the dams have consumed capital that could have been spent on alternative economic activities in Mali (i.e. opportunity costs) and therefore need to be valued accordingly.

In valuing the capital costs, several assumptions have been made. Firstly, the capital stock is assumed to depreciate by $0.5 \%$ per year. Of the rehabilitation costs made in the past, we assume that $25 \%$ are additional investments in fixed capital (e.g. roads, canals, turbines). Moreover, in the early stages of operation of the dam and the irrigation scheme, the operational and maintenance $(\mathrm{O} \& \mathrm{M})$ costs are assumed to be $2 \%$ of the value of the capital stock (WCD 2001). Due to increased failure and wearing of the infrastructure, this fraction increases by $1.25 \%$ per year. Therefore, the more recent the 
dams and irrigation schemes, the lower the O\&M costs. For example, the present O\&M costs of Markala barrage and the Sélingué dam are assumed to be $4.21 \%$ and $2.73 \%$ respectively.

International funding agencies and national donors have covered most of the investments in dams and irrigation schemes in Mali. In the case of Office du Niger, for example, the French Government covered the initial investment costs, while the French and Dutch Ministries of Development Cooperation funded most of the rehabilitation costs. The World Bank also provided substantial funds to rehabilitate the Markala dam and its irrigation area. It is not clear whether any, interest is actually being paid by Office du Niger and the Sélingué dam. Yet, even if the funds were provided as a grant, and organisations of both dams do not pay interest on these funds, the capital still represents a scarce good and therefore should be valued accordingly. After all, the same funds could have been invested in other economic activities. Therefore, we assume an opportunity cost of capital of $8 \%$ of the actual capital stock.

\subsection{Sélingué}

Limited information is available on the financial costs of the Sélingue dam. As shown in Table 3, an initial investment of around $€ 53.4$ million was made in the period 1980 to 1982 for the construction of the Sélingué dam and associated infrastructural works. In 1993, Energie du Mali received a credit of US\$ 4.8 million for rehabilitating the hydroelectric scheme. This was followed by the Sélingué Rehabilitation Project, which ran from 1996-2002, requiring funds of US\$34.2 million. The goals of the rehabilitation project were i) to increase the thermal capacity of the system, ii) to support overall capacity building and iii) to establish a long-term institutional framework. This brings the total investment costs to more than $€ 92$ million, assuming an exchange rate of 1 between the US\$ and the euro.

Table 3 Financial costs of Sélingué dam (in $€$ ).

\begin{tabular}{lcccc}
\hline Year & Initial Investment & $\begin{array}{c}\text { Rehabilitation by } \\
\text { Energie du Mali } \\
\text { (funded by IDA) }\end{array}$ & $\begin{array}{c}\text { Rehabilitation by } \\
\text { World Bank and } \\
\text { European } \\
\text { Development Bank }\end{array}$ & Total costs \\
\hline $1980-1982$ & $53,361,793$ & & & $4,800,000$ \\
1993 & & $4,800,000$ & & $34,210,000$ \\
$1996-2002$ & $53,361,793$ & $4,800,000$ & $34,210,000$ & $92,371,793$ \\
Total & &
\end{tabular}

\subsection{Office du Niger}

Table 4 shows the investments that have been made in the past 80 years. These estimates include the costs of the construction and rehabilitation of the dam itself, as well as the development of the irrigation area, which presently measures around 70,000 hectares. As previously mentioned, the irrigation area is expected to expand by another 40,000 ha by 2030. The cost of the expansion of the irrigation area is estimated at $€ 2,300$ per hectare. On the basis of projections provided by experts, it is assumed that the irrigation area will grow by approximately 1,500 ha per annum. 
Table $4 \quad$ Financial costs of Office du Niger (in $€$ ).

\begin{tabular}{lcccr}
\hline Year & Initial Investment & $\begin{array}{c}\text { Rehabilitation by } \\
\text { French \& Dutch }\end{array}$ & $\begin{array}{c}\text { Rehabilitation by } \\
\text { World Bank }\end{array}$ & \multicolumn{1}{c}{ Total costs } \\
\hline $1919-1920$ & $2,700,000$ & & & $42,700,000$ \\
1945 & $161,000,000$ & & & $161,000,000$ \\
1979 & & $3,030,000$ & & $3,030,000$ \\
$1979-1983$ & & & $4,500,000$ & $4,500,000$ \\
1985 & & $43,770,000$ & & $43,770,000$ \\
1988 & $23,400,000$ & & $23,400,000$ \\
$1989-1992$ & & & $9,000,000$ & $9,000,000$ \\
$1989-1997$ & & & $57,800,000$ & $48,800,000$ \\
1993 & & & & $23,900,000$ \\
1995 & & $20,780,000$ & & $20,780,000$ \\
1996 & & $4,990,000$ & & $4,990,000$ \\
Total & $163,700,000$ & $119,870,000$ & $62,300,000$ & $385,870,000$ \\
\hline
\end{tabular}

Source: Schreyger (2002), Slob (2002).

\subsection{Fomi dam}

The construction of the Fomi dam was initially considered several years ago. As such, most of the background information originates from the late nineties (Agence Canadienne pour le Développement International, 1999). Still, limited financial information is available. The 42 meter high dam is expected to produce $374 \mathrm{GWH}$ per month and is scheduled to provide irrigation to almost 30,000 ha of cultivable land (UNIDO 2004). As with the Office du Niger, the costs of the irrigation area are estimated at $€ 2,300$ per hectare. It is assumed that the irrigation area will develop over a period of 15 years, gradually expanding by 2,000 ha per year. The construction period of the Fomi dam itself will take 44 months. Table 5 shows the limited financial information available.

Table 5 Initial investment costs estimated in 1999 (in million 1999 US\$).

\begin{tabular}{lc}
\hline Cost item & Detailed cost estimate by SNC \\
\hline Hydraulic works & 199 \\
Transmission infrastructure & 62 \\
Engineering \& management & 27 \\
Total costs & 288 \\
\hline
\end{tabular}

Source: Agence Canadienne pour le Développement International (1999).

\subsection{Electricity}

Theoretically, the installed capacity of the Sélingué hydropower plant is $47.6 \mathrm{MW}$. This means that the plant could produce $34.8 \mathrm{GWh}$ per month if all four turbines are available and the reservoir is full. In reality, the maximum generated energy is around $25 \mathrm{GWh}$ per month, which is around $70 \%$ of the theoretical value. The specified firm energy of 18 MW corresponds to about $13 \mathrm{GWh}$ per month. This is the average estimate that is applied in our CBA. The Sélingué power plant is expected to produce a stable supply of electricity over time. The value added of one kilowatt-hour is FCFA75. The exchange rate applied for the FCFA against the euro is 660 . 
Because the Fomi hydropower plant is scheduled to have a maximum installed capacity of $90 \mathrm{MW}$ at full head, we assume that the power production is twice as big as that of Sélingué: $26 \mathrm{GWh}$ per month. It will take 6 years for the Fomi power plant to be in full operation. The same value of one kilowatt-hour is assumed. Figure 4 shows the pattern of revenues from electricity supply.

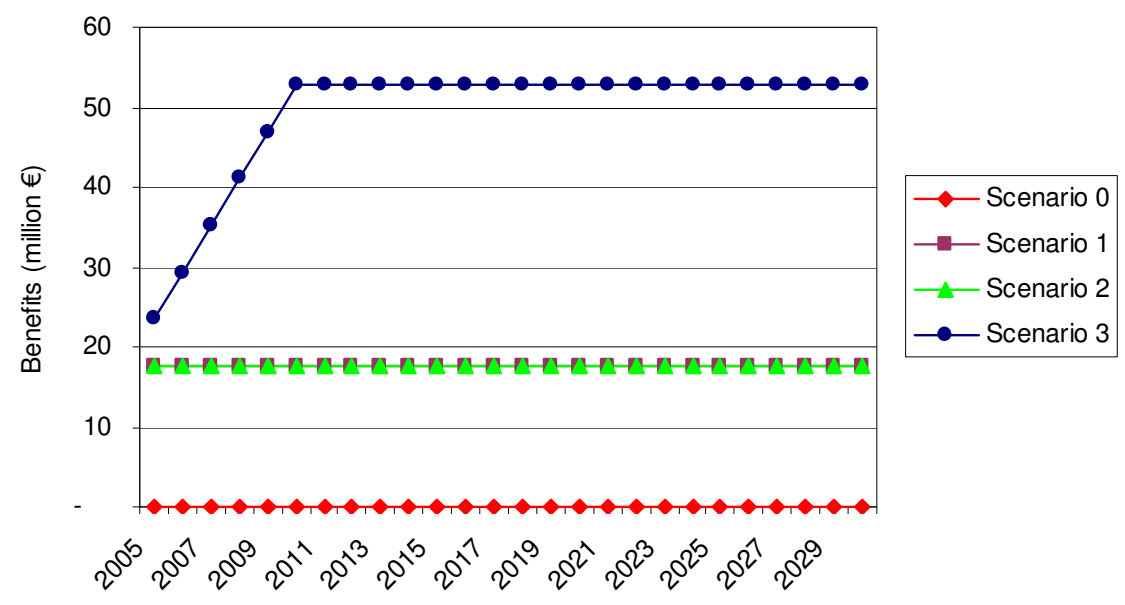

Figure 4 Predicted revenues from electricity production for the four scenarios.

\section{Benefits}

A number of economic activities downstream are heavily affected by management interventions (dams and irrigation regimes) upstream. This section focuses specifically on the indirect costs and benefits downstream.

\subsection{Fisheries}

The available data on traded fish and the variation of the inundation zone over time (see Chapter 5, Zwarts et al. 2005) allow for the estimation of a production function for fish catch. The main variable that determines the variation in fish trade and catch is the biological production of fish, which in turn is determined by the maximum water level reached during the preceding year in Akka. This relationship has already been described for the total fish production and over a shorter period: Welcomme (1986a) for the period 1967 - 1975 and Laë (1992a) for the period 1966 - 1989. An updated analysis is shown in Figure 5.

Fishing is one of the leading economic activities in the Inner Niger Delta. The economic value of the fishing industry varies due to fluctuations in catch levels as well as variations in the price of fish. Figure 6 shows the monthly price variation for different types of fish production based on the average for the period 1998 to 2002. One possible explanation for the seasonal fluctuation is the level of catch, which is also seasonally dependent. The flooding season causes a significant decline in the overall catch. The catch triples during the dry season. Monthly variations are not taken into account in the simulation model. Thus, the average value of fish is estimated at FCFA 500 per kg (OPMannuals). 


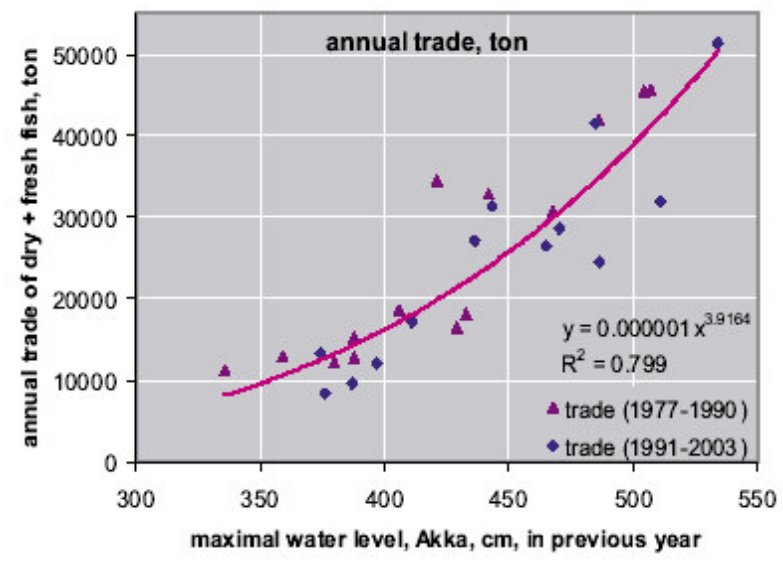

Figure 5 Annual trade (ton fresh fish equivalents) of dry and fresh fish in the Inner Niger Delta as a function of the maximal inundation in the previous year.

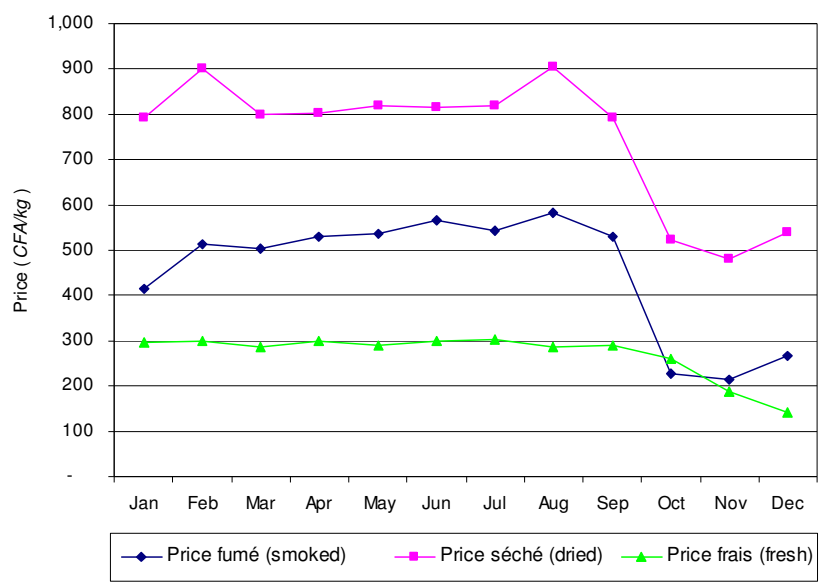

Figure 6 Seasonal fluctuations of fish prices on the basis of data from the period 1972 to $2002(F C F A / \mathrm{kg})$.

Source: OPM-annuals.

Fisheries are heavily affected by changes in the inundation areas. Figure 7 shows how the fishery sector varies over time. The short-term fluctuations are caused by the standard variation in climate conditions. It is clear that with each additional dam in operation, the fishing industry is reduced further. Therefore, scenario 0 generates the highest fisheries benefits. The difference in fish catch is particularly pronounced during wet years.

\subsection{Livestock}

Pastoralists and their livestock depend heavily on water in the Delta. Without sufficient inundation, there is not enough food for the animals. To determine the dependence of cattle on the availability of water, numbers of cattle have been correlated with several hydrological parameters. As most pastoral livestock in Africa depends on precipitation, rainfall is a plausible parameter to test for. However, the situation in the Inner Niger Delta is atypical in the sense that it has an exceptionally large inundation area. 


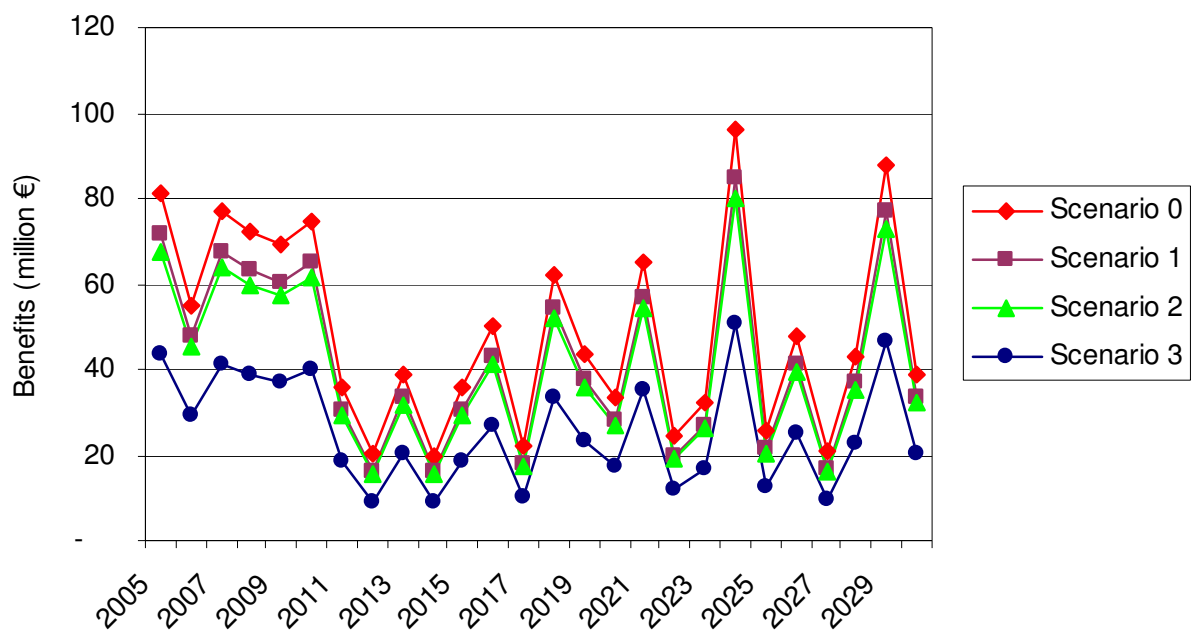

Figure 7 Benefits in the fishery sector over time for the four scenarios (in million $€ /$ year).

Nomadic pastoralists move into the delta when the flood arrives. Strong correlations between livestock numbers and river height/size of the inundation area are therefore more likely to be found compared to correlations between livestock and precipitation.

Because the duration of the flood best explains changes in livestock numbers, this would also be the most appropriate variable to use in the simulation of the four scenarios. However, it seems a nearly impossible task to generate predictions based on hydrology with a temporal resolution of days. Therefore, we focus on the 'next-best' option. The habitat suitable for bourgou (vegetation utilised as fodder) is used as the explaining variable for estimating changes in livestock populations in the four scenarios.

Production functions have been estimated for the two regions of Mopti and Tombouctou. These capture the relationship between numbers of livestock (cattle and sheep/goats) and the surface area of optimal habitat for bourgou. Because the data make no distinction between sheep and goats, both are analysed under the same heading. Patterns were very irregular during the collapse of livestock populations in the early 1980s; therefore, all regression analyses were conducted for the 'recovery-period' after the drought of the 1980s. The production functions for the two regions are presented in Table 6.

Table 6 Production functions for number of livestock (y) as a function of optimal habitat (x) in Mopti and Tombouctou.

\begin{tabular}{lcccc}
\hline Livestock & Mopti & $\mathrm{R}^{2}$ & Tombouctou & $\mathrm{R}^{2}$ \\
\hline Cattle & $\mathrm{y}=393 \mathrm{x}+797,389$ & 0.69 & $\mathrm{y}=149 \mathrm{x}+332,511$ & 0.44 \\
Sheep \& goat & $\mathrm{y}=506 \mathrm{x}+2,572,123$ & 0.43 & $\mathrm{y}=947 \mathrm{x}+160,717$ & 0.51 \\
\hline
\end{tabular}

Livestock is valued on the basis of its meat value. It is assumed that (on average) $2 \%$ of the sheep and goat populations, and $8 \%$ of the cattle population, is slaughtered and marketed each year (Annual reports of the Direction Générale de l'Elevage). The weight of the animals varies across the district, but the average weight of cattle and sheep is calculated at $85 \mathrm{~kg}$ and $9 \mathrm{~kg}$ respectively. The average meat price for cattle and sheep in this analysis is $600 \mathrm{FCFA} / \mathrm{kg}$ and $400 \mathrm{FCFA} / \mathrm{kg}$ respectively. 
Figure 8 shows the fluctuations of the livestock sector for the four scenarios. Several interesting observations can be made. The scenarios show less sensitivity to short-term climate fluctuations, compared to long-term fluctuations. This results from cattle's ability to move to greener fields. Still, livestock is vulnerable to long-term droughts. This is demonstrated by the collapse of livestock populations in the period 2010 to 2013, which are modelled as extremely dry years. Another lesson drawn from Figure 8 is that in extremely wet years (i.e. 2005 to 2010) the presence of dams can actually benefit cattle, sheep and goats. This is due to the fact that livestock heavily depends on the availability of bourgou. If the water level is too high, bourgou is negatively affected, and so are the cattle. By tempering extreme peak flows and thus creating a more optimal bourgou habitat in extremely wet years, scenario 3 performs well in periods with abundant rain. By reducing the peak flow far beyond optimal levels in extremely dry years, scenario 3 performs poorly during the years with exceptionally little rain.

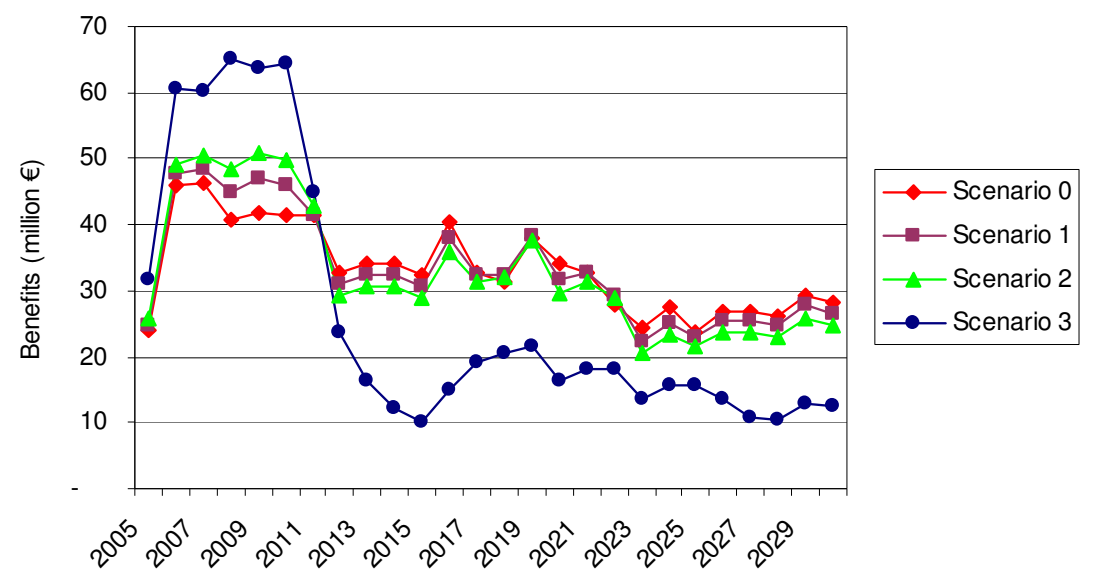

Figure 8 Benefits in the livestock sector over time for the four scenarios (in million $€ /$ year).

\subsection{Agriculture}

Agricultural production is not simply a curvilinear function of rainfall. For example, some of the rice in Mali is grown on the floodplain and is highly dependent on the flood level. In Figure 9, rice production in the Delta is plotted against the flood level in Sofara. The data are split into two groups: years with less than $400 \mathrm{~mm}$ annual rainfall, and years with more than $400 \mathrm{~mm}$ rainfall. In all cases where rainfall was greater than the average, production was high at about 1200 tonnes. In all these years, however, the flood level was also high. When rainfall was less than the average, the flood level has a very dominant effect on the production, which varies between 0 and 1400 tonnes.

The agricultural sector in and around the Inner Delta can be subdivided into irrigated agriculture and flood-related agriculture. The production functions derived in these chapters have been applied in the simulation model. Despite the observed fluctuations in the price of crops, the value added of rice and 'other crops' is assumed to be FCFA 95,000 and 75,000 per ton, respectively. Figure 10 shows the simulated scenarios for the agricultural sector. The main contribution to agricultural production in Mali comes from Office du Niger. The present production of Office du Niger is assumed to expand by 1,500 ha per year. 


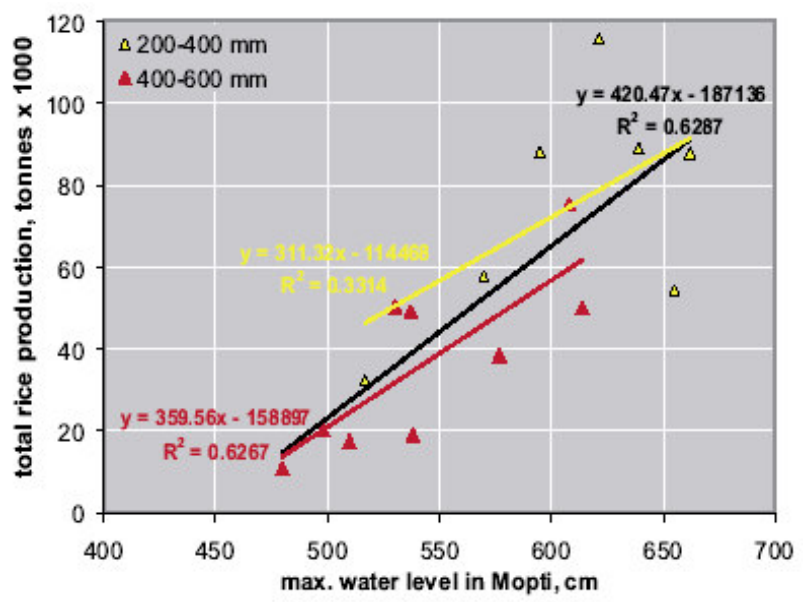

Figure 9 The total rice production in the region of Mopti (excluding the area of ORM) as a function of the peak flood level in Mopti. Symbols with different colours indicate years with above and below average rainfall. The function is given for all data (1985-2001), as well as for the two levels of rainfall.

Source: DRAMR.

The other important source of rice, sorghum, and other crops in the region is expected to be the Fomi dam. Parallel to the implementation of the hydropower capacity, the irrigation fields are developed over a period of 15 years, at 2,000 ha per year.

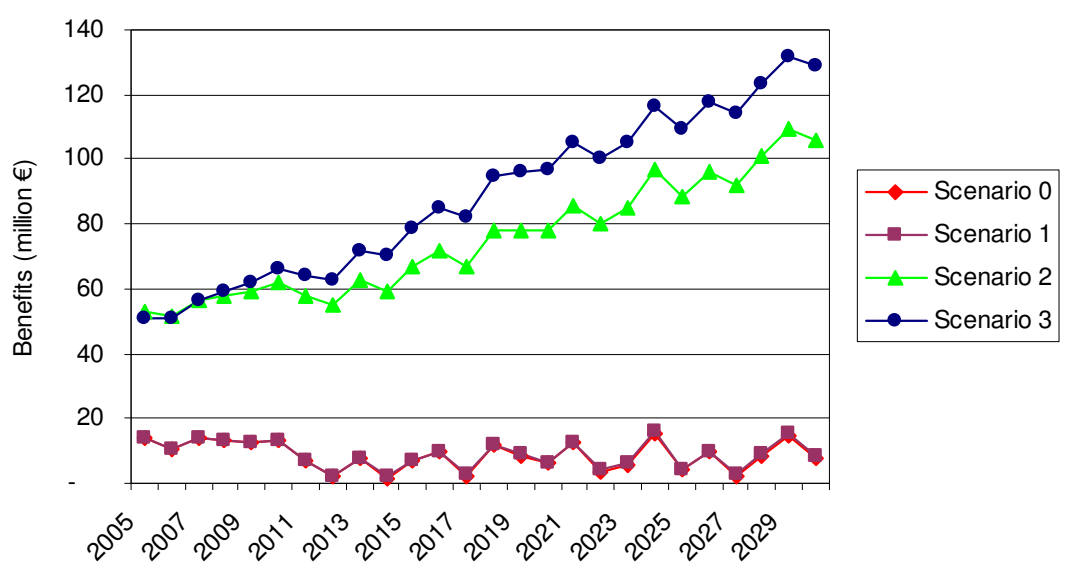

Figure 10 Benefits in the agricultural sector over time for the four scenarios (in million $€ /$ year).

\subsection{Transport}

The Niger River plays an important role in the transport of goods and people.

Particularly during the wet season, boats are the most popular means of transport in the Delta. Not only does river transport allow people and goods to reach remote places, transport by boat is also relatively inexpensive compared to road transport. As shown in Table 7, distances in Mali are significant. 
In assessing the transport value of the Niger River, a distinction is made between the big boats (with a maximum capacity of around 400 people and 350 tons of goods) and smaller boats (with a capacity of around 10-20 people and 1-5 tons of freight).

Table 7 Transport routes on the Niger River.

\begin{tabular}{lc}
\hline Route & Distance (in km) \\
\hline Koulikoro-Segou & 180 \\
Segou-Macina & 154 \\
Macina-Mopti & 170 \\
Mopti-Niafunke & 225 \\
Niafunke-Diré & 86 \\
Diré-Tombouctou & 85 \\
Tombouctou-Gao & 408 \\
\hline
\end{tabular}

Big boats need at least 3 to 4 meters of water depth, while smaller boats can still navigate at a depth of 1 meter. Table 8 summarises the current capacity, and the economic value of the fleet of big boats. Information on the smaller boats is not readily available. Therefore we assume that the fleet of smaller boats has a similar capacity to that of larger boats.

Table $8 \quad$ Underlying assumptions of transport analysis for the big boats.

\begin{tabular}{lrlrl}
\hline Data & Persons & Unit & Freight & Unit \\
\hline Maximum capacity & 64,613 & Persons & 34,125 & Tons \\
Maximum capacity & 58 & Million person-km & 31 & Million ton-km \\
Price per unit & 13 & FCFA/Person/km & 127 & FCFA/ton per km \\
Value of transport & 727 & Million CFA & 3,890 & Million CFA \\
\hline
\end{tabular}

Source: Based on interviews with shipping companies and boat owners.

Dams and irrigation schemes have an impact on the navigational potential of the Niger River by reducing the water level in the wet season while providing additional flow during the dry season. Reducing the deep-water navigational period specifically affects larger boats. The additional depth of the Niger in the dry season is particularly useful for smaller boats. The number of navigational days for the four scenarios at various water levels is shown in Figure 11. Comparing Scenario 0 (no dams) and Scenario 3 (three dams), shows that the latter scenario would lead to an additional 82 days of navigation for smaller boats while the operational season of larger boats would be reduced by 20 days.

The results of the model simulation for the transport sector are shown in Figure 12. The scenarios that perform best are those with the Sélingue dam and Office du Niger in existence. These dams secure sufficient downstream water in the dry season for the smaller boats without causing too much disruption to the larger boats in the wet season. In extremely dry years, the Fomi dam performs better in terms of transport, while in wet years, an absence of dams is preferable. 


\subsection{Biodiversity}

The biodiversity of the Inner Niger Delta is unique. Therefore, Mali's biodiversity has an economic value. To capture this value, a survey was carried out in the Netherlands, in which Dutch citizens were asked about how much financial support they would give to protect birds in the Netherlands and in sub-Saharan Africa.

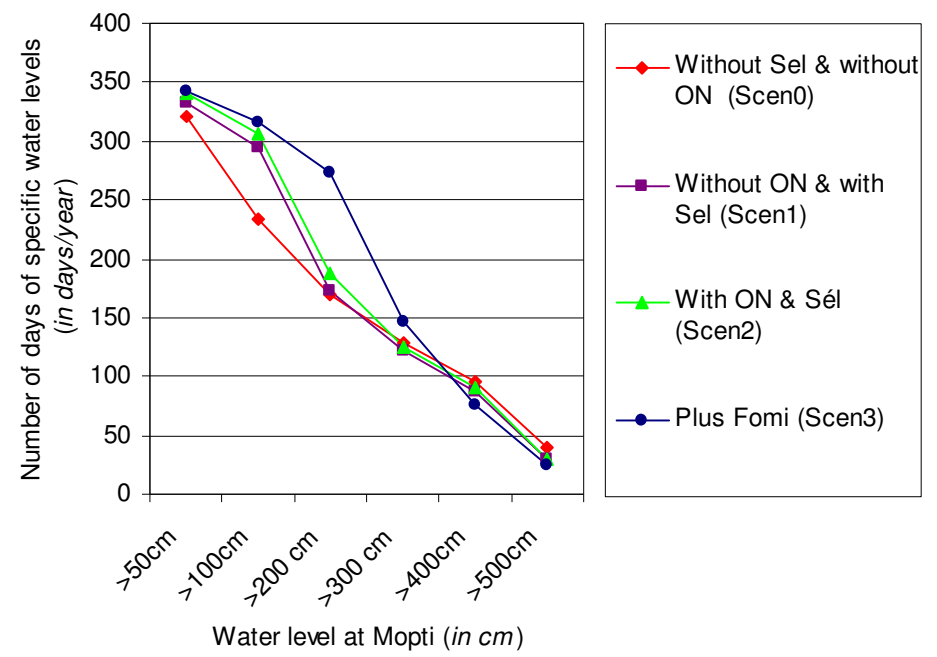

Figure 11 Average seasonal variation of navigational depths at Mopti for the different scenarios based on the simulations for the period 1982-2002 (in number of days in an average year).

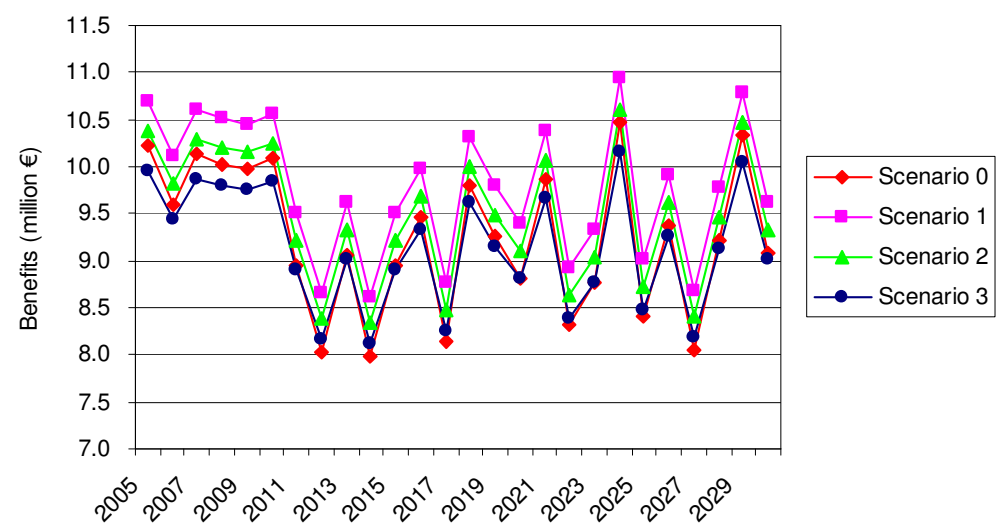

Figure 12 Benefits in the transport value over time (in million $€ /$ year).

The results of this survey are reported in Van Beukering and Sultanian (2005). In summary, the study shows that birds are important for many people in the Netherlands. More than half of the 800 respondents were willing to pay for the protection of birds' habitats. The average willingness to pay is estimated at around $€ 15$ per household per year. If extrapolated across Europe, the fund available for migratory bird protection is more than $€ 2$ billion.

The Inner Niger Delta is an important winter residence for many European migratory birds. On the basis of the distribution of European migratory birds in Africa, we assume that $1 \%$ of these $€ 2$ billion is available for bird protection in Mali in 2005. The level of funds is assumed to vary in relation to ecological values. As explained in the previous 
Section, the ecological value of birds in the Inner Niger Delta and the irrigation areas is estimated at 7,019 'ecological points' in scenario 0 (see Chapter 12, Zwarts et al. 2005). To put economic values on the level of biodiversity, the price of one ecological point is set at $€ 3,200$ (i.e. $1 \%$ of $€ 2$ billion divided by 7,019 ). Because the ecological score varies over time for the four scenarios, a hypothetical economic value for biodiversity was derived. As opposed to the other sectors, the biodiversity estimate is highly hypothetical and is likely to be significantly higher or lower in reality. However, because we consider excluding this value from the CBA more detrimental than including it, we decided on the latter approach. Because the approach is experimental and therefore subject to critique, the impact of our assumptions on the final result is tested in the sensitivity analysis.

The results of the simulation modelling are shown in Figure 13. Birds in the Inner Niger Delta depend heavily on bourgou. Bourgou does not grow well in extremely deep waters. This is why scenario 2 scores somewhat better than scenario 0 in extremely wet years. However, across the full period, a situation without dams generates the highest biodiversity value. Scenario 3 leads to an extremely low value of biodiversity in the Delta. The reduced area of inundation that results from the Fomi dam forces the water birds to concentrate in limited areas. This not only restricts the availability of food but also makes them more vulnerable to human exposure.

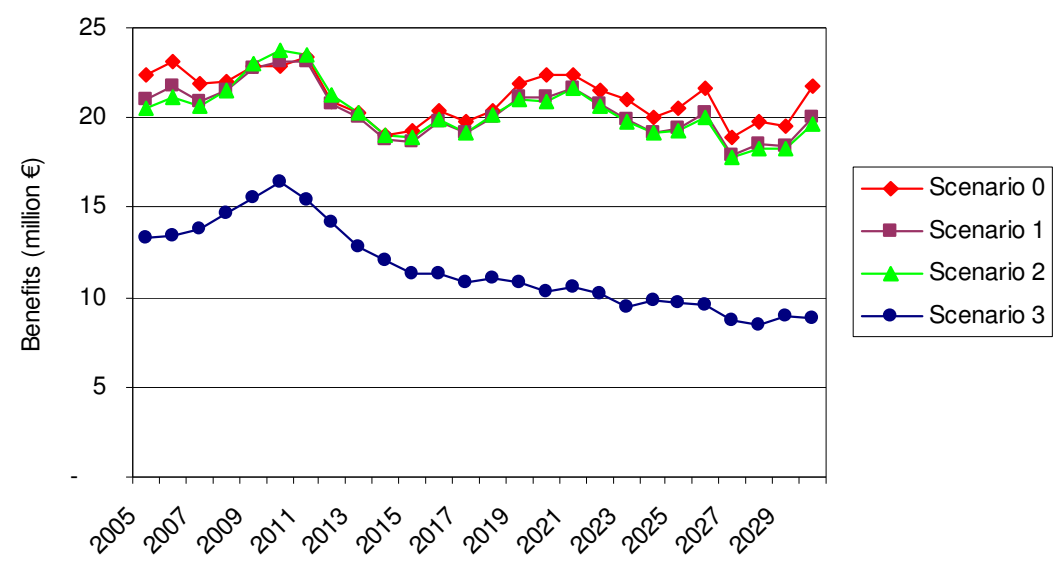

Figure 13 Biodiversity benefits over time for the four scenarios (in million $€ / y e a r$ ).

\section{Cost benefit analysis}

\subsection{Benefits and costs over time}

Figure 14 presents the overall costs and benefits for the four scenarios, over the full period of 2005 to 2030 . If strictly looking at the benefits, which are shown in the upper part of Figure 14, it is clear that more dams also lead to higher overall benefits. In practically every year, the benefits of scenario 3 (i.e. 3 dams) exceed the benefits of scenario 2 (i.e. 2 dams), which in turn exceeds the benefits of scenario 1 (1 dam). In other words, human intervention can lead to higher revenues for the society at large. Yet, higher benefits do not necessarily imply higher welfare levels. The cost of each scenario should also be taken into account.

The middle part of Figure 14 shows the overall costs over time for the four scenarios. Not surprisingly, a similar ranking pattern to that of the benefits graph arises. Obviously, 
3 dams cost more than 2 dams, and 2 dams cost more than 1 dam, etc. Yet, costs differ from benefits in two ways. Firstly, the difference between the scenarios is much more pronounced in the cost graph. In particular, the combination of three dams (scenario 3) requires significant investments and maintenance costs. This is mainly due to the fact that the Fomi dam still needs to be built, while the Office du Niger and Sélingué dam are already in operation. Secondly, compared to the benefits, the costs are much more predictable and constant over time as they are independent of climate conditions.

The lower part of Figure 14 illustrates the net benefits over time for the four scenarios. Net-benefits are defined as the overall benefits minus the overall costs. The ranking of the scenarios on the basis of net-benefits changes over time. Due to the high initial investments needed for the Fomi dam, scenario 3 generates low net-benefits in the first few years. However, these increase as soon as the Fomi dam gradually goes into operation. Typically, the net-benefits of scenario 2 exceed those of scenario 3 throughout the full period. From the fluctuations of the net-benefits in Figure 14, it can also be concluded that dams are particularly beneficial during years of abundant rain. During wet years the foregone benefits downstream are significantly less.

\subsection{Net present value}

The next step in analysing the benefits and costs of the four scenarios is to sum up the annual benefits and costs over time. Economists aggregate values over time by converting the annual costs and benefits into present values (PV) by discounting. Discounting is the practice of placing lower values on future benefits and costs as compared to present benefits and costs, reflecting people's preferences for the present rather than the future. The discount rate applied in this study is 5\%. To demonstrate the impact of this rate, a sensitivity analysis for a range of discount rates is also performed.

Table 8 shows the PV of the overall net-benefits of the four scenarios i) aggregated over the full period (column 2) and ii) as annual values (column 3). These values represent the total net economic value of each scenario. Both columns show that scenario 2 generates the highest net-benefits while scenario 3 generates the least. This implies that the addition of the Fomi dam has a negative impact on the overall economy.

To analyse the individual economic impact of the three combinations of dams, the difference between dam scenarios 1, 2 and 3 and scenario 0 (no dams) is considered. These additional net-benefits of the three dam scenarios are calculated by subtracting the overall net-benefits of scenario 0 from the net-benefits of scenario 1, 2 and 3. Columns four and five of Table 8 show the marginal PV of the aggregated and annual net-benefits of the three dam scenarios. By looking at the difference between scenario 2 and 3, the additional net-benefit of the Fomi dam to the present situation (Markala and Sélingué) can be determined. By building the Fomi dam, society at large will lose more than $€ 500$ million (i.e. $€ 121+€ 380$ million), which implies an annual loss of $€ 35$ million (i.e. $€ 8.5$ $+€ 26.4$ million). The Sélingué dam generates additional net-benefits of $€ 68.5$ until 2030. The Markala dam is the most economically feasible dam of the three, generating aggregated net-benefits of $€ 312$ million (i.e. $€ 380$ - $€ 69$ million). This is equal to almost $€ 22$ million per year (i.e. $€ 26.4$ - $€ 4.8$ million). 


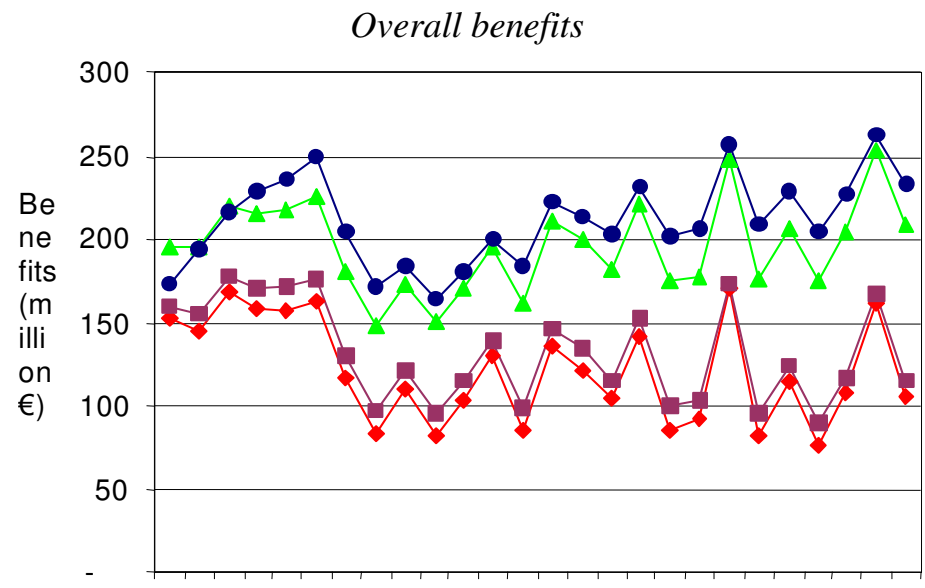

20052007200901 20120152017201902 202302520272029

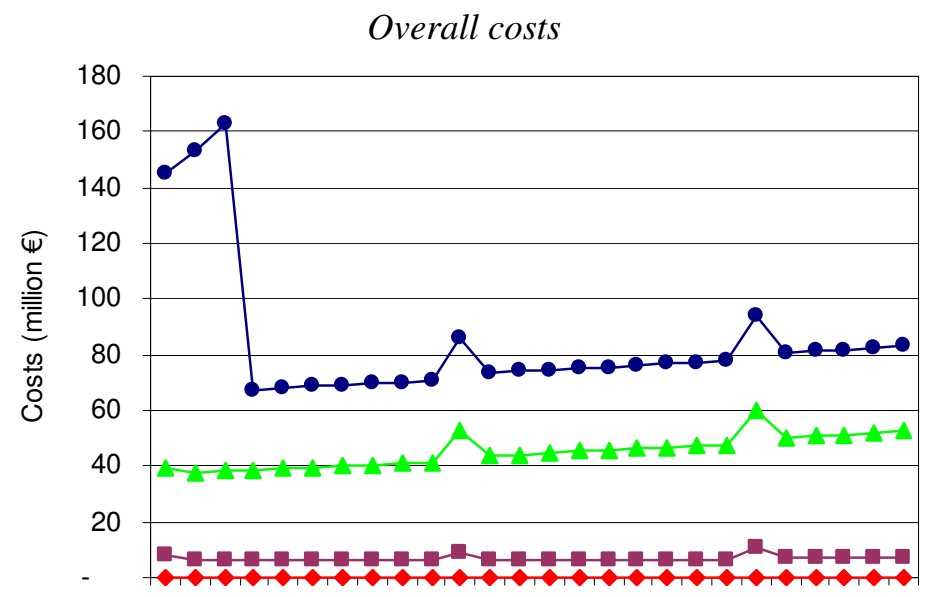

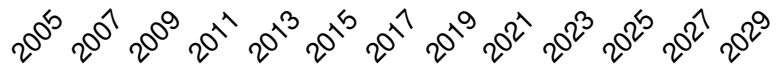

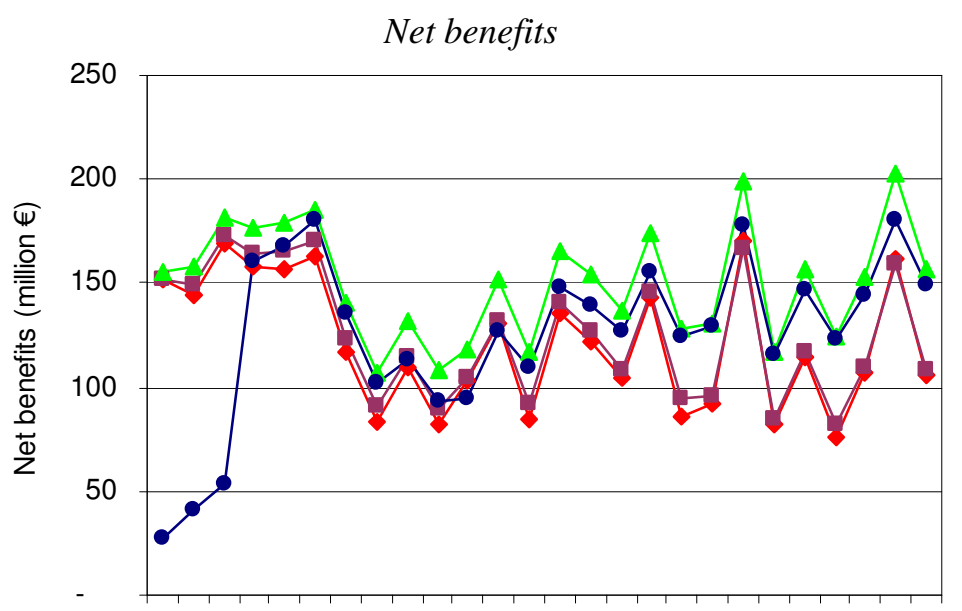

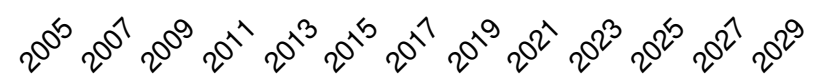

$\multimap$ Scenario $0 \multimap-$ Scenario $1 \multimap$ Scenario $2 \longrightarrow$ Scenario 3

Figure 14 Overall costs and benefits of the four scenarios over time (2005-2030). 
Table $8 \quad$ The present value (PV) of the net-benefits of the four dam scenarios. These were calculated by subtracting the overall costs from the overall benefits (net benefits) and comparing the changes of scenarios 1,2 and 3 relative to scenario 0 (marginal) which represents an absence of dams.

\begin{tabular}{lcccc}
\hline & \multicolumn{2}{c}{ Overall } & \multicolumn{2}{c}{ Marginal } \\
\hline Scenario & $\begin{array}{c}\text { PV of net-benefits } \\
\text { (in million } \epsilon \text { ) }\end{array}$ & $\begin{array}{c}\text { PV of annualised } \\
\text { net-benefits } \\
\text { (in million } € \text { per year) }\end{array}$ & $\begin{array}{c}\text { PV of net-benefits } \\
\text { (in million } \epsilon \text { ) }\end{array}$ & $\begin{array}{c}\text { PV of annualised } \\
\text { net-benefits } \\
\text { (in million } € \text { per year) }\end{array}$ \\
\hline Scenario 0 & 1,903 & 132 & - & - \\
Scenario 1 & 1,971 & 137 & 68.5 & 4.8 \\
Scenario 2 & 2,283 & 159 & 380.2 & 26.4 \\
Scenario 3 & 1,781 & 124 & -121.8 & -8.5 \\
\hline
\end{tabular}

\subsection{Sectoral distribution}

The additional net-benefits of the scenarios are comprised of changes in various economic sectors. The sectors have been described individually in the previous section. The configuration of the different sectoral benefits is shown in Figure 15. The negative values represent the accumulative financial costs of each scenario. The costs clearly increase more than proportionally with the addition of the Fomi dam. Although these additional costs are partly compensated for by additional electricity and agricultural benefits, the loss in fisheries, livestock and biodiversity are also substantial. The impact of the Office du Niger irrigation area and Sélingué dam are much less pronounced. Figure 15 also shows that a society without dams (scenario 0 ) mainly generates income through fisheries and livestock. No electricity is produced and agriculture remains rather limited.

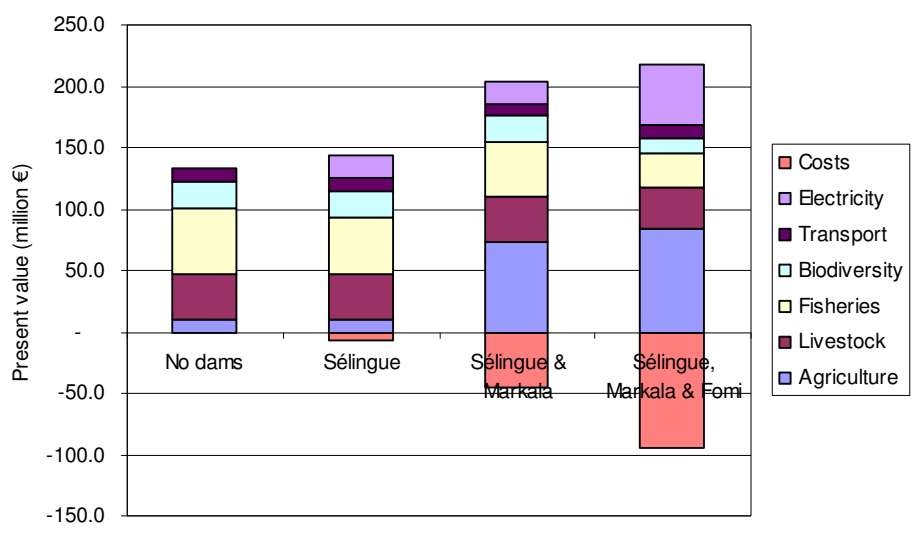

Figure 15 Allocation of the PV of the related costs and benefits of the four scenarios (26 years, discount rate 5\%).

\subsection{Spatial distribution}

An important dimension of the study is the spatial distribution of the benefits under the different scenarios. Besides changes in the absolute level of welfare, dams are likely to cause transfers of benefits from one region to another. Figure 16 shows the allocation of the overall benefits between the Inner Niger Delta and the Upper Niger region. The 
Upper Niger region includes all those districts in Mali and Guinea in which dams generate economic activities such as irrigated agriculture and hydropower. In Mali these district are Segou, Macina, Niono and Yanfolila. The pattern in Figure 16 clearly shows that with each additional dam, benefits are transferred from the Inner Niger Delta to the Upper Niger region. This transfer is especially significant in scenario 3. This implies that the Fomi dam will substantially benefit Guinea at the expense of Mali.

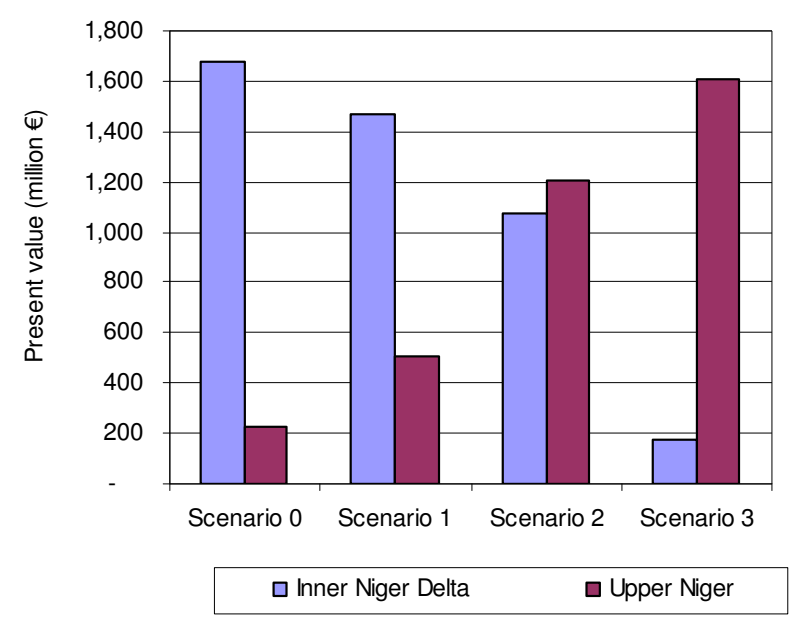

Figure 16 Spatial distribution of the overall benefits divided between the Inner Niger Delta and the Upper Niger region, which includes Mali and Guinea.

Figure 17 shows a more detailed spatial allocation of the overall benefits of the four scenarios across the various districts. In a situation without dams, Mopti and Ténenkou are the economic centres of the Niger-dependent districts. In the present situation (with both Markala and Sélingué in full operation) Ségou dominates the river-related economy. Due to the reduced water discharge in the Niger River caused by the Fomi dam, Ségou's economic benefits decline, while the Guinean economy increases substantially.

Another way of looking at spatial distribution is to consider the benefits per person in each district. Figure 18 shows the different levels of per capita benefits derived from the Niger River for the four scenarios. Some explanation is required here. The current trends in population change have been exogenously extrapolated for the period 2005 to 2030. In reality, these trends are likely to depend on the scenario because more economically successful regions usually attract immigrants from the less prosperous regions. On the one hand, this may imply that the available statistical data underreport the real income generated in the economic sectors considered. On the other hand, it should be acknowledged that the results refer to the river-related sectors only. A number of other important economic activities (such as road transport, retail and commerce) have not been included in the estimates presented in this study. Finally, note that the per capita benefit for the other Upper Niger region in scenario 3 cannot be calculated because the Guinean population benefiting from the Fomi dam is unknown. 


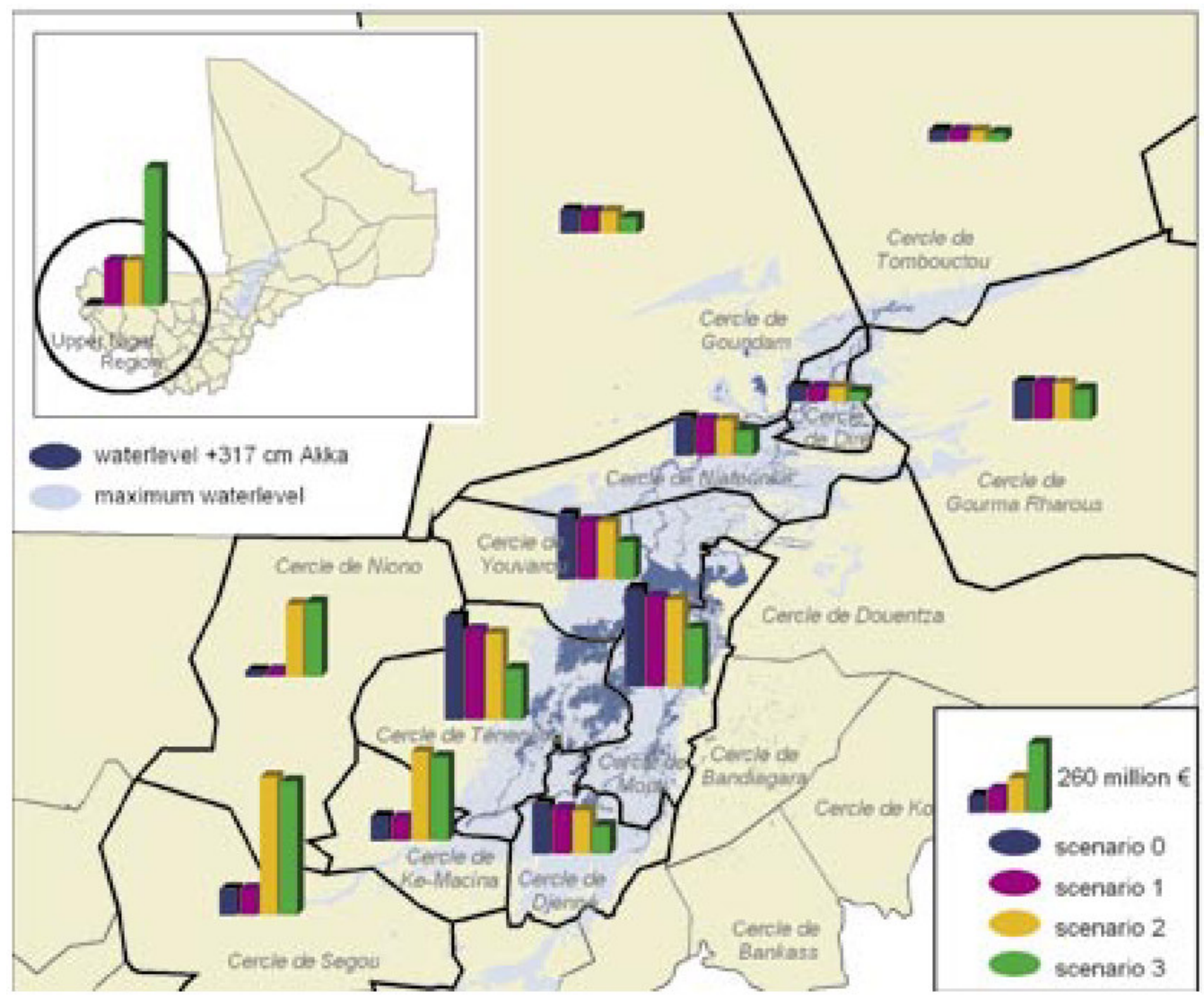

Figure 17 Spatial distribution of the overall benefits across the different districts for the four scenarios in million $€$ (26 years, discount rate 5\%).

Despite these possible methodological caveats, several important lessons can be drawn from the data shown in Figure 18. Clearly, those districts that are located in the Inner Niger Delta exhibit a significant decline in per capita income with an increase in the number of dams. The economic benefits accruing to the Upper Niger district obviously increase with the number of dams. Only the establishment of the Fomi dam has a negative impact on per capita income. For the average Malian citizen, the Markala and Sélingué dams somewhat improved the level of welfare. The average river-related benefit increases with each dam from $€ 44$ (scenario 0 ), to $€ 48$ (scenario 1 ) and $€ 68$ (scenario 2). The Fomi dam is expected to reduce the Niger-associated welfare of the Malian population from $€ 68$ to $€ 52$ per capita.

Finally, the spatial distribution of effects on different economic sectors can also be presented. The current allocation of benefits (scenario 2) is presented in Figure 19. In this situation, the region "other Upper Niger" represents the district Yanfolila only. The configuration of benefits varies significantly between the different districts. Gourma depends mostly on livestock benefits, while Téenenkou and Mopti are typical fishery districts. Ségou, Macina and Niono benefit mostly from revenues derived from irrigated agriculture, while Yanfolila benefits predominantly from power generation and some fishery income from the reservoir. 


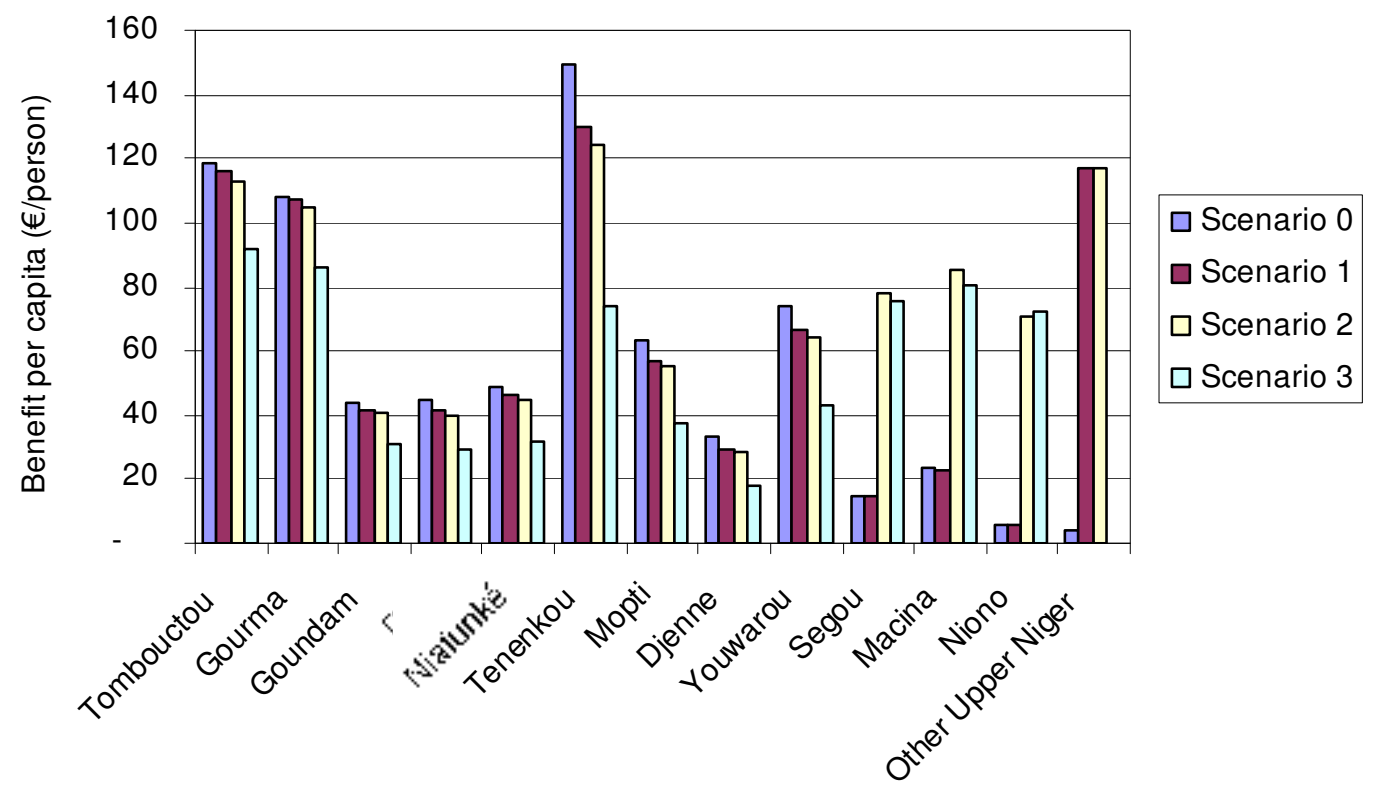

Figure 18 Spatial distribution of the overall per capita benefits generated from the Niger River across the different districts for the four scenarios in $€ /$ person (26 years, discount rate 5\%).

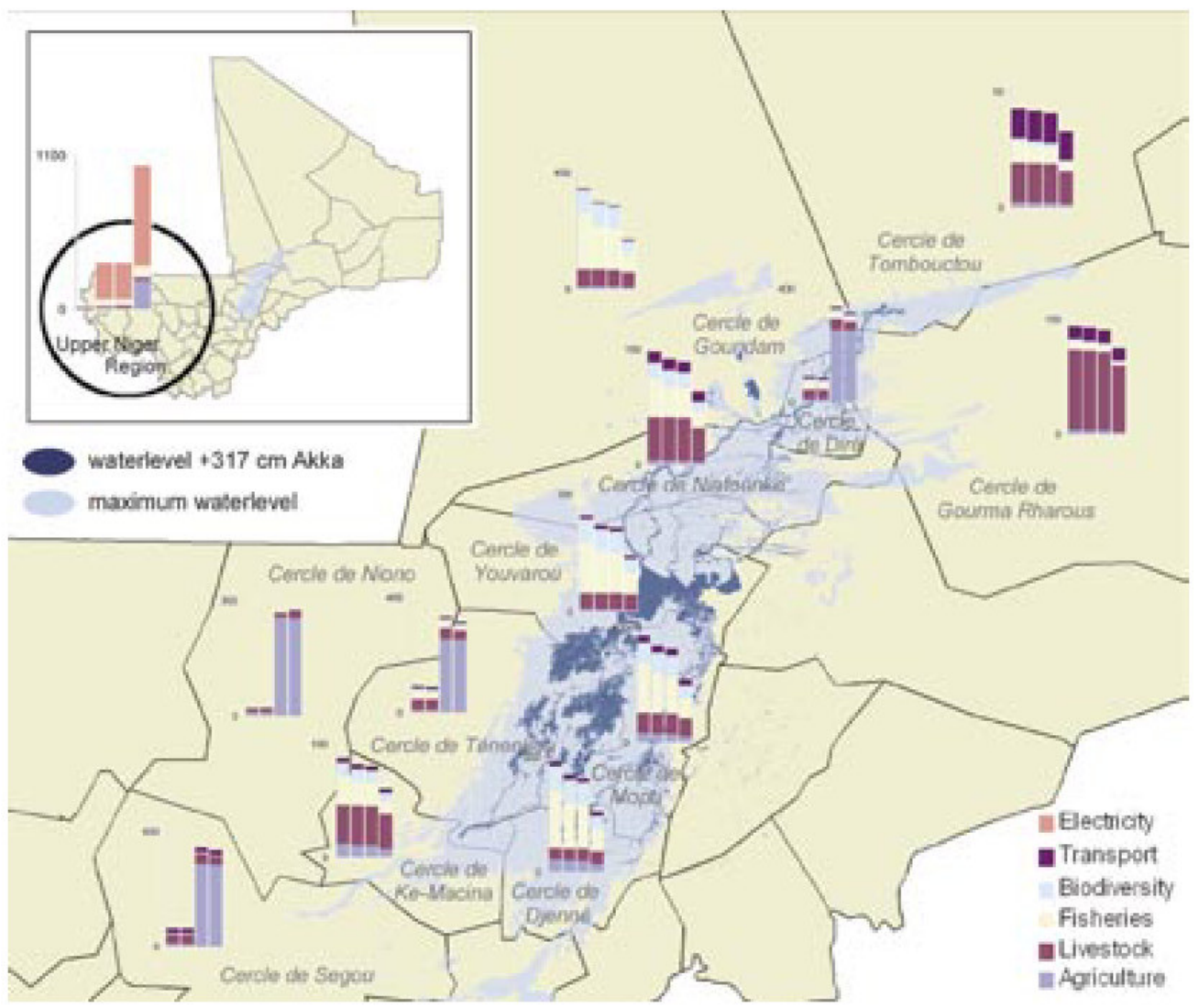

Figure 19 Spatial distribution of the benefits across the different sectors for each district for the four scenarios in million $€$ (26 years, discount rate 5\%). 


\subsection{Sensitivity analysis}

A large number of assumptions were made to generate the above results. This is necessary, given the constraints of data and the time available for this research. These assumptions need not be problematic as long as the results are relatively robust vis-à-vis changes in the assumed parameter values. At this stage, the sensitivity of the outcome is tested for three of the most crucial assumptions: the discount rate, climatic conditions and the valuation of biodiversity.

The standard discount rate used for the economic analysis of the management of the Niger River is 5\%. Figure 20 shows the results of this sensitivity analysis for a range of 0 to $15 \%$. Two observations can be made from the graph. Firstly, at a discount rate of zero percent (which implies no discounting occurs) all dam combinations generate a positive NPV of the net-benefits. Secondly, the curves do not intersect. This means that the ranking of the three scenarios remains the same regardless of the discount rate applied. Therefore, the results are robust as far as the discount rate is concerned.

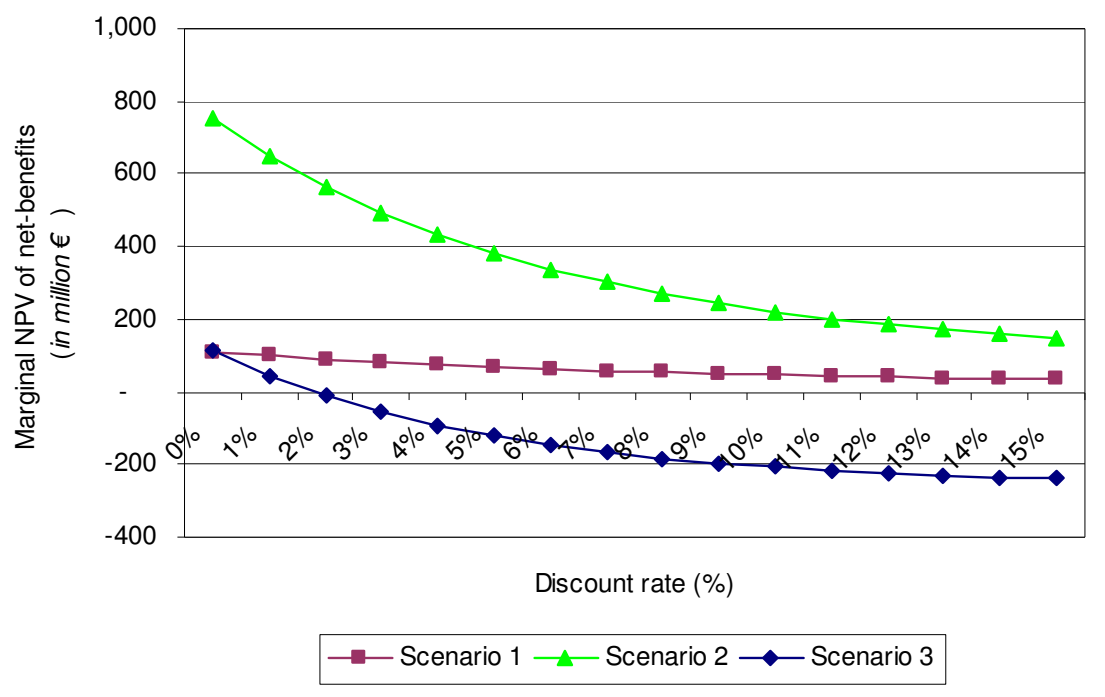

Figure 20 Sensitivity analysis of the impact of the discount rate on the NPV of the net-benefits (in million $€$ ).

The second crucial assumption in the study concerns the climatic conditions in the Upper Niger region. On the basis of the previous 75 years, it was estimated that rainfall declines by $3.5 \mathrm{~mm}$ each year. Due to the overall trend of global warming, this rate of decline may well accelerate over the coming decades. To test the impact of an increased climate change trend, the reduction in rainfall was subsequently increased by $25 \%, 50 \%, 100 \%$, and $150 \%$ for the different scenarios. The results of this sensitivity analysis are shown in Figure 21, for the Inner Niger Delta and the Upper Niger region. Both regions suffer from increased drought conditions, albeit to a different degree. For all three scenarios, the Inner Niger Delta is much more vulnerable to drought than the Upper Niger, especially in the case of the presence of the Fomi Dam. 


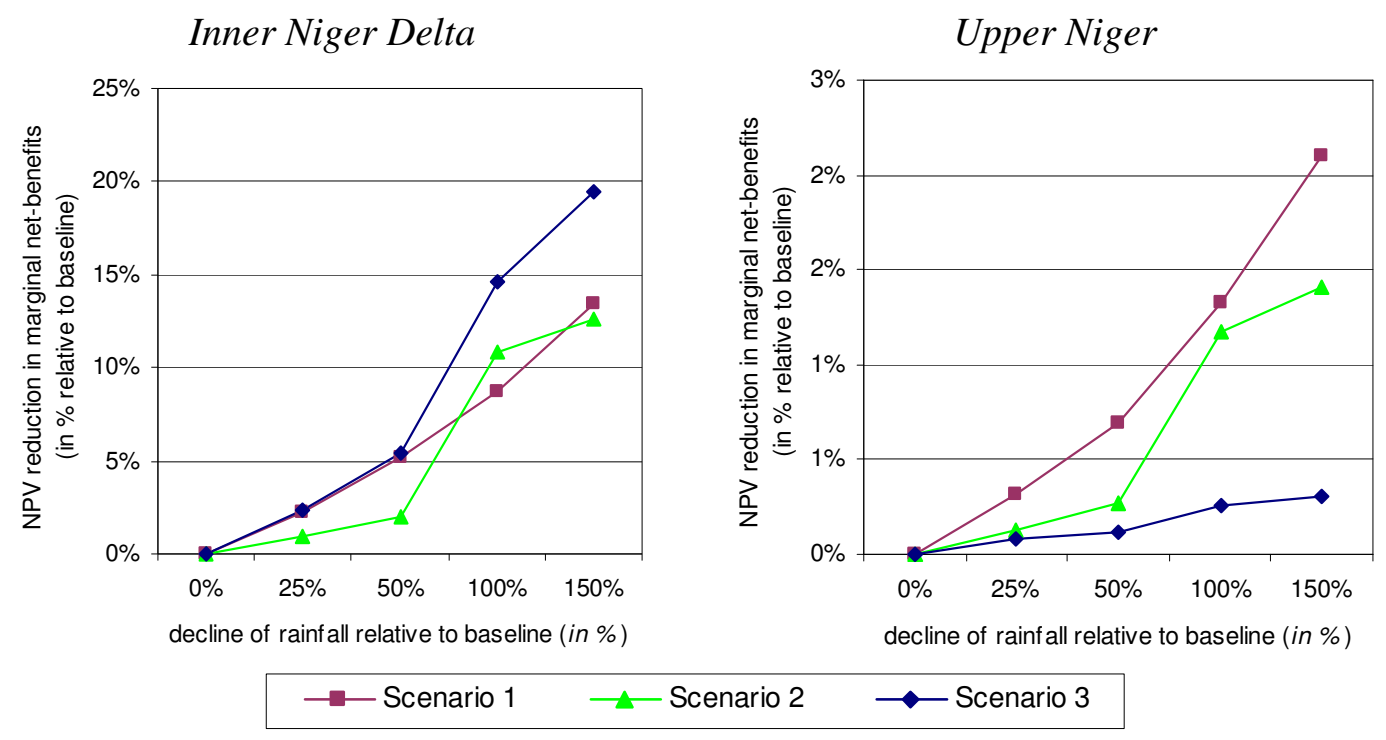

Figure 21 Sensitivity analysis of the impact of more extreme climate conditions on the $N P V$ of the net-benefits (in million $€$ ).

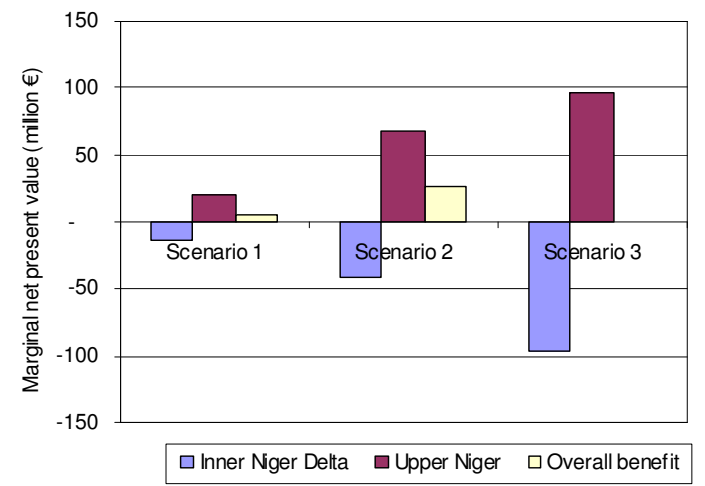

Figure 22 Sensitivity analysis of the impact of the decimation of the biodiversity value on the NPV of the net-benefits (in million $€$ ).

The final assumption that is tested relates to the impact of the biodiversity value on the final outcome. At present, the biodiversity value is mainly an expression of preferences by European citizens. In other words, more biodiversity in the Delta leads to higher welfare in Europe. Only a limited share of this benefit is actually transferred to the communities in the Inner Niger Delta. Because the biodiversity value is a real value measured in Europe, and because it is expected that this European biodiversity value will increasingly be used in Mali to protect birds and other types of nature, the estimated value is actually incorporated in the cost benefit analysis in this study. It may be argued, however, that the extent to which the measured biodiversity value will ever benefit the Delta's residents is significantly smaller. Therefore we test the sensitivity of the final outcome by assuming that only $10 \%$ of the expressed biodiversity value will actually benefit the economy.

The results are shown in Figure 22. The additional net-benefits of the dams have slightly improved as a result of the decline in the biodiversity value. The economic feasibility of the Sélingué and the Markala dams remain intact. The feasibility of the Fomi Dam is 
somewhat improved: losses in the Inner Niger Delta are at least compensated for by the gains in the Upper Niger region. Nevertheless, the addition of the dams still leads to a decline in the additional net-benefits. This sensitivity test shows how biodiversity considerations in the Inner Delta do not fully change economic decisions by themselves; yet by making it part of the equation, biodiversity can play a crucial role.

\section{Conclusions}

After combining information provided by hydrologists, ecologists, engineers, fishery experts, and agriculturalists, the economic analysis is the final step in a long series of scientific exercises. Despite the fact that simplifying assumptions were made, several conclusions can be drawn from the results of this study:

- The economic value of dams in the Niger River depends predominantly on the amount of water diverted from the river. The Sélingué and the Markala dams appear to be economically feasible. They jointly generate $€ 26.4$ million of benefits per year to society at large. The addition of the Fomi dam would reduce economic prosperity by $€ 35$ million per year;

- The benefits accrue to various sectors and vary widely depending on the level of water diversion from the Niger River. The additional financial costs of the Fomi dam are only partly compensated by additional electricity and agricultural benefits. Moreover, the indirect loss in fisheries, livestock and biodiversity downstream override these direct revenues. These negative downstream effects are less pronounced in case of the Office du Niger irrigation zone and the Sélingué dam;

- Besides changes in the absolute level of welfare, dams are likely to cause transfers of benefits from one region to the other. The results clearly show that with each additional dam, benefits are transferred from the Inner Niger Delta to the Upper Niger region. This transfer is especially significant in case of the addition of the Fomi dam, which substantially benefits Guinea at the expense of Mali;

- Dams in the Niger have mixed effects on poverty. The population of the Inner Delta experiences a significant decline in per capita income with an increase in the number of dams. The per capita economic benefits of the Upper Niger population increase with additional dams. The average river-related benefit per person increases with each additional dam from $€ 44$ (no dams), to $€ 48$ (Sélingué) to $€ 68$ (Sélingué and Markala). The Fomi dam is expected to reduce the river associated welfare of the Malian population from $€ 68$ to $€ 52$ per capita;

- Finally, the sensitivity analysis of climatic conditions reveals that the Inner Delta (and, to a lesser degree, the Upper Niger region) suffer from increased drought. The vulnerability of the Inner Niger Delta is raised substantially by the construction of the Fomi Dam.

\section{References}

Acharya, G. (2000). Approaches to valuing the hidden hydrological services of wetland ecosystems. Ecological Economics, 35, 63-74.

Acharya, G. \& Barbier, E.B. (2000). Valuing groundwater recharge through agricultural production in the Hadejia-Nguru wetlands in northern Nigeria. Agricultural Economics, 22, 247-259. 
Agence Canadienne pour le Développement international (1999). Etudes de réactualisation du dossier de faisabilité du barrage de Fomi: Rapport de faisabilité. - Montréal: SNC-Lavalin International.

Asian Development Bank (1995). Sector Synthesis of Postevaluation Findings in the Irrigation and Rural Development Sector. Manila.

Aylward, B., Berkhoff, J., Green, C., Gutman, P., Lagman, A., Manion, M., Markandya, A., McKenney, B., Naudascher-Jankowski, K., Oud, B., Penman, A., Porter, S., Rajapakse, C., Southgate, D. \& Unsworth. R. (2000). Financial, Economic and Distributional Analysis. Thematic Review III.1 prepared as an input to the World Commission on Dams, Cape Town, www.dams.org.

Barbier, E.B. (2000). Valuing the environment as input: applications to mangrove-fishery linkages. Ecological Economics, 35, 47-61.

Barbier, E.B. \& Strand, I. (1998). Valuing mangrove-fishery linkages: a case study of Campeche, Mexico. Environmental and Resource Economics, 12, 151-166.

Beukering, P.J.H. van \& Sultanian, E. (2005). How important are birds to us? Results of a survey on the perception of the environment by the Dutch. Working Paper. Institute for Environmental Studies, Vrije Universiteit Amsterdam.

Brander, L.M., Florax, R.J.G.M. \& Vermaat, J.E. (2004). The Empirics of Wetland Valuation: A Comprehensive Summary and a Meta-Analysis of the Literature. Environmental and Resource Economics. Forthcoming.

Bystorm, O., Anderson, H. \& Gren, I.M. (2000). Economic criteria for using wetlands as hydrogen sinks under uncertainity. Ecological Economics, 35, 35-45.

Dietz, T., Ostrom, E. \& Stern, P.C. (2003). The Struggle to Govern the Commons, Science, 302, 1907-1912.

Ellis, G. \& Fisher, A. (1987). Valuing the environment as an input. Journal of Environmental Management, 25, 149-156.

Fisher, A.C., Krutilla, J.V. \& Ciccheti, C.J. (1972). The economics of environmental preservation. American Economic Review, 62, 605-619.

Freeman, A.M. (1993). The Measurement of Environmental and Resource Values: Theory and Methods, Washington DC: Resources for the Future, pp. 516.

GoM (2002). Poverty Reduction Strategy Paper. Document prepared and adopted by the Government Of Mali, Bamako.

Gutman, P. (1993). Involuntary Resettlement in Hydropower Projects. The World Bank, Washington, DC.

IDA \& IMF (2003). Joint Staff Assessment of the Poverty Reduction Strategy Paper of the Republic Of Mali. International Development Association (IDA) and the International Monetary Fund (IMF), Washington DC.

Kosz, M. (1996). Valuing riverside wetlands: the case of Donace-Anav National Park. Ecological Economics, 16, 109-127.

Loth, P. (editor) (2004). The Return of the Water: Restoring the Waza Logone Floodplain in Cameroon. IUCN, Gland, Switserland and Cambridge, UK.

Mäler, K.G. (1992). Production function approach in developing countries. In Vincent, J.R., Crawford, E.W. \& Hoehn, J.P. (eds). Valuing Environmental Benefits in Developing Countries. East Lansing Special Report 29, Michigan State University.

Ostrom, E. (1990). Governing the Commons: The Evolution of Institutions for Collective Action, New York: Cambridge University Press. 
Ostrom, E. (1999). Coping with tragedies of the commons. Annual Review of Political Science, 2, 493-535.

Bonneval, P., Kuper, M., Tonneau, J-P. (2002). L'Office du Niger, grenier à riz du Mali: Succès économiques, transitions culturelles et politiques de développement; Le fil de l'eau et la part des homes. La Librairie de Cirad, Montpellier Cedex.

Schreyer (2002). Personal communication.

Slob, A. (2002). Personal communication.

Söderqvist, T., Mitsch, W.J. \& Turner, R.K. (2000). Valuation of wetlands in a landscape and institutional perspective. Ecological Economics, 35, 1-6.

Soils Incorporated (Pty) Ltd and Chalo Environmental and Sustainable Development Consultants (2000). Kariba Dam Case Study. Prepared as an input to the World Commission on Dams, Cape Town.

World Commission on Dams. Orange River Development Project, South Africa. Case Study prepared as an input to the World Commission on Dams, Cape Town, www.dams.org. 